\title{
ASSESSMENT OF MEASUREMENT ERRORS AND DYNAMIC Calibration Methods FOR Three Different TipPing BUCKET RAIN GAUGES
}

\author{
Vinayak S. Shedekar ${ }^{a *}$, Kevin W. King ${ }^{b}$, Norman R. Fausey ${ }^{b}$, Alfred BO Soboyejo ${ }^{a}$, R. \\ Daren Harmel ${ }^{c}$, Larry C. Brown ${ }^{a}$
}

a Department of Food, Agricultural and Biological Engineering, The Ohio State University, 590 Woody Hayes Drive, Columbus, Ohio 43210, USA.

b USDA/ARS - Soil Drainage Research Unit, 590 Woody Hayes Drive, Columbus, Ohio 43210, USA.

c USDA/ARS - Grassland Soil and Water Research Laboratory, 808 East Blackland Rd., Temple, Texas 76502, USA.

* Corresponding Author: Dept. of Food, Agricultural and Biological Engineering, The Ohio State University, 590 Woody Hayes Drive, Columbus, Ohio 43210, USA. Phone: +1(203) 321-5568; E-mail: shedekar.1@osu.edu

Abstract. Three different models of tipping bucket rain gauges (TBRs), viz. HS-TB3 (Hydrological Services Pty Ltd), ISCO-674 (Isco, Inc.) and TR-525 (Texas Electronics, Inc.), were calibrated in the lab to quantify measurement errors across a range of rainfall intensities $\left(5 \mathrm{~mm} \cdot \mathrm{h}^{-1}\right.$ to $\left.250 \mathrm{~mm} \cdot \mathrm{h}^{-1}\right)$ and three different volumetric settings. Instantaneous and cumulative values of simulated rainfall were recorded at 1, 2, 5, 10 and 20 -min intervals. All three TBR models showed a substantial deviation $(\alpha=0.05)$ in measurements from actual rainfall depths, with increasing underestimation errors at greater rainfall intensities. Simple linear regression equations were developed for each TBR to correct the TBR readings based on measured intensities $\left(\mathrm{R}^{2}>0.98\right)$. Additionally, two dynamic calibration techniques, viz. quadratic model $\left(\mathrm{R}^{2}>0.7\right)$ and T vs. $1 / \mathrm{Q}$ model $\left(\mathrm{R}^{2}=>0.98\right)$, were tested and found to be useful in situations when the volumetric settings of TBRs are unknown. The correction models were successfully applied to correct field-collected rainfall data from respective TBR models. The calibration parameters of correction models were found to be highly sensitive to changes in volumetric calibration of TBRs. Overall, the HS-TB3 model (with a better protected tipping bucket mechanism, and consistent measurement errors across a range of rainfall intensities) was found to be the most reliable and consistent for rainfall measurements, followed by the ISCO-674 (with susceptibility to clogging and relatively smaller measurement errors across a range of rainfall intensities) and the TR-525 (with high susceptibility to clogging and frequent changes in volumetric calibration, and highly 
intensity-dependent measurement errors). The study demonstrated that corrections based on dynamic and volumetric calibration can only help minimize- but not completely eliminate the measurement errors. The findings from this study will be useful for correcting field data from TBRs; and may have major implications to field- and watershedscale hydrologic studies.

Keywords. Precipitation, Tipping bucket rain gauge; Calibration; Accuracy; Rainfall measurement; Hydrologic monitoring

\section{INTRODUCTION}

In the United States, weather records have been collected and compiled at many stations for more than a century. The current network of meteorological stations consists of greater than 10,000 weather stations (Cook, 2010), spread throughout the country. Precipitation is being monitored at more than 8,000 of these stations. Standard 8 " nonrecording precipitation gauges (SNRG) are the official precipitation measurement instrument for the U.S. climate station network monitored by the National Weather Service (NWS). Approximately $30 \%$ of all weather stations use one or more of three main types of automated recording gauges: Tipping Bucket Rain gauges (TBRs), Universal Weighing rain gauges, and Fischer and Porter-Belfort rain gauges (Groisman et al. 1999). Tipping bucket rain gauges became popular because of their simple, durable, and inexpensive design; and most importantly, their adaptability to remote areas. They can be easily installed in remote areas and connected to a variety of monitoring and/or recording devices. Because of these advantages, TBRs are often used for continuous and reliable precipitation measurements in watershed-scale monitoring and research studies.

\subsection{ACCURaCy OF Precipitation Data COllected/Measured by TBRs:}

The accuracy of point precipitation measurements is often a concern due to underestimation, ranging from $5 \%$ to 40\% (Legates, 1987; Legates and Willmott 1990; Groisman and Legates, 1994). Underestimations result from wetting and evaporation losses, gauge height, wind-induced turbulence at the gauge orifice, extremely light or intense rainfall, and snowfall (Parsons, 1941; Neff, 1977; Sevruk and Hamon, 1984; Legates and Willmott, 1990; Groisman et al., 1999; Sansom and Gray, 2002; Upton and Rahimi, 2003; Molini et al., 2005; Lanza and Stagi, 2009; Lanza and Vuerich, 2009). Underestimations are generally more pronounced in the winter compared to 
summer (Legates and DeLiberty, 1993). At intensities greater than $25 \mathrm{~mm} \mathrm{~h}^{-1}$, the underestimations increase nonlinearly with increases in intensity (Marsalek 1981; Alena et al., 1990; Humphrey et al., 1997).

The errors in TBR measurements can be categorized as either systematic/mechanical or random. Systematic/mechanical biases in the TBRs can be attributed to both catching and counting inaccuracies which are in turn related to the positioning and mechanics and/or electronics of the instrument. Positioning refers to wetting, splashing, evaporation and wind-induced errors. Mechanical or electronic errors include limited tipping rate, and double tips due to an out of level instrument. Systematic errors are due to design or material limitations and hence are more predictable. Random errors refer to the biases caused by some unforeseen factors, such as leakage or damage to the gauge, human errors (introduced by observers measuring and recording data), interference from animals, etc. Both systematic and random errors may cause biases in a positive or negative direction (Servuk, 1979).

Calibration of TBRs can be carried out in two ways: static (volumetric) calibration and dynamic calibration. A detailed description of both of these methods has been given by Humphery et al. (1997). Static or volumetric calibration refers to adjusting the volume required to tip the bucket, which corresponds to the resolution of the TBR. Dynamic calibration refers to estimation of the under-catchment errors by calibrating the TBR while the buckets are in motion. Several dynamic calibration approaches have been proposed to account for the systematic errors associated with TBRs (Calder and Kidd, 1978; Marsalek, 1981; Niemczynowicz, 1986; Costello and Williams, 1991; Legates, 1992; Humphrey et al., 1997; Fankhauser, 1998; Vasvàri, 2005). Some of the methods involve physical or mechanical adjustments in the TBRs prior to data collection, while others involve post-collection processing of data for elimination of errors. Although, most of these dynamic calibration approaches have been studied extensively and implemented into monitoring protocols (Vasvàri, 2005), few studies report the interaction of volumetric and dynamic calibration. Furthermore, the validity of correction methods developed in lab experiments needs to be tested for correcting actual field collected data by the TBRs.

The objectives of this study were to: 1) calibrate three commonly used TBR models and quantify the measurement errors associated with each of them as affected by the interaction between volumetric and dynamic calibration; 2) develop statistical models to correct the rainfall measurements by the three TBRs; 3) validate and compare the performance of the statistical models using field-measured rainfall data; and 4) describe and discuss the implications of errors in TBRs to hydrologic studies. 


\section{Materials ANd Methods}

Based on their widespread use in hydrologic and water quality monitoring projects, the three TBR models (table

1) selected for this study were: HS-TB3 (Hydrological Services Pty Ltd, New South Wales, Australia); ISCO-674

(Teldyne, Isco, Lincoln, NE, USA); and TR-525 (Texas Electronics, Inc., Dallas, TX, USA).

Table 1 Specifications of TBRs used during volumetric and dynamic calibration

\begin{tabular}{llll}
\hline Rain gauge Make $\rightarrow$ & HS-TB3 & ISCO-674 & TR-525 \\
\hline Manufacturer & Hydrological Services Pty Ltd & Isco, Inc. & Texas Instruments Inc. \\
Model & TB3 & 674 & $525 \mathrm{I}$ \\
Resolution & $0.254 \mathrm{~mm}(0.01 \mathrm{in})$. & $0.254 \mathrm{~mm}(0.01 \mathrm{in})$. & $0.254 \mathrm{~mm}(0.01 \mathrm{in})$. \\
Receiver diameter, D & $20.3 \mathrm{~cm}(8 \mathrm{in})$. & $20.3 \mathrm{~cm}(8 \mathrm{in})$. & $15.4 \mathrm{~cm}(6.06 \mathrm{in})$. \\
Receiver area & $324.3 \mathrm{~cm}^{2}$ & $324.3 \mathrm{~cm}^{2}$ & $186.3 \mathrm{~cm}^{2}$ \\
Nominal bucket volume per tip $\left(\mathrm{V}_{\text {tip }}\right)$ & $8.24 \mathrm{ml}$. & $8.24 \mathrm{ml}$. & $4.73 \mathrm{ml}^{.}$ \\
Tipping time \pm standard error $(\mathrm{sec})$ & $0.36 \pm 0.038$ & $0.32 \pm 0.019$ & $0.38 \pm 0.036$ \\
Volumetric settings used in lab experiment: & & \\
Lowest & $6.0 \mathrm{ml}$. & $7.0 \mathrm{ml}$. & $4.15 \mathrm{ml}$. \\
Medium & $7.5 \mathrm{ml}$. & $8.1 \mathrm{ml}$. & $4.7 \mathrm{ml}$. \\
Highest & $8.3 \mathrm{ml}$. & $9.0 \mathrm{ml}$. & $5.4 \mathrm{ml}$. \\
\hline
\end{tabular}

\subsection{LABORATORY ASSESSMENT}

The laboratory assessment was accomplished through a series of calibrations: volumetric calibration of rain gauges; calibration of the supply pump, and dynamic calibration of rain gauges (fig. 1). The data from lab experiments were used for estimating errors and developing statistical models for each TBR.

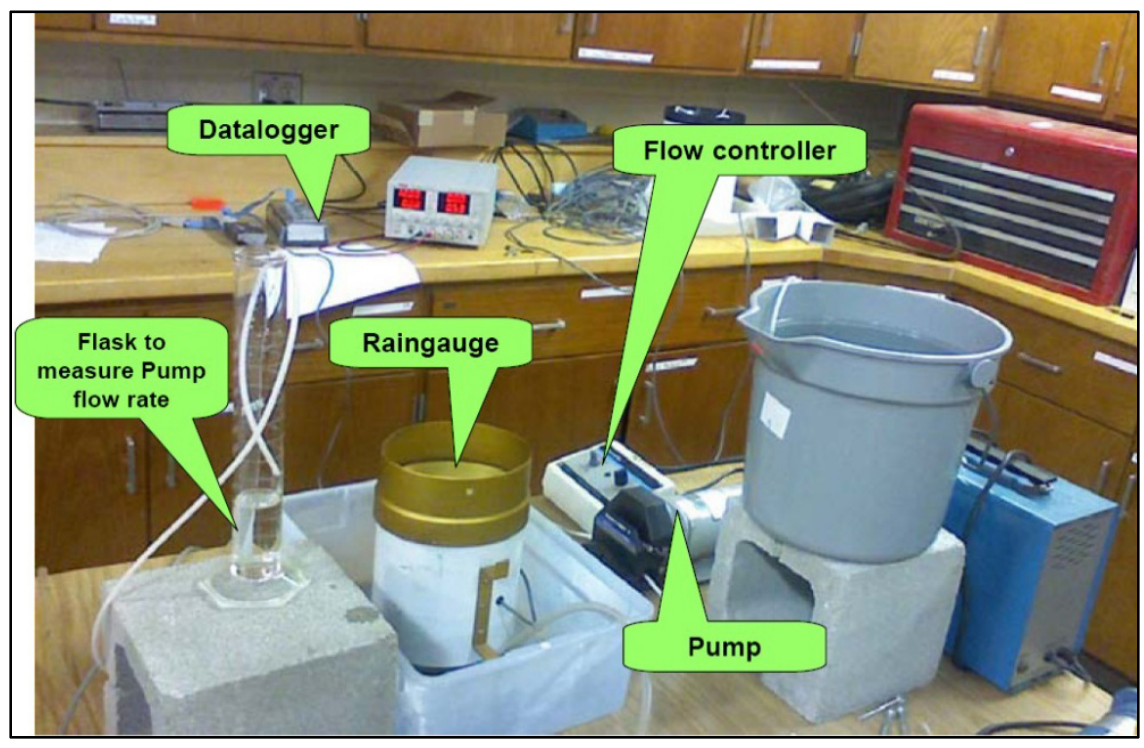

Fig. 1 Experimental set up for TBR calibration in laboratory (Model TR-525 is shown). 
Volumetric calibration of each TBR model was conducted prior to dynamic calibration. Each TBR was placed on a level platform, and the tipping bucket mechanism was tested for volume of water required to tip the bucket. A 10$\mathrm{ml}$ pipette held at the same height as the outlet of the funnel was used to supply water. One bucket tip was equivalent to $0.254 \mathrm{~mm}$ of rainfall. The nominal bucket volumes, defined as volumes equivalent to a rainfall depth of $0.254 \mathrm{~mm}$, were: HS-TB3 $(8.24 \mathrm{ml})$; Isco-674 $(8.24 \mathrm{ml})$; and TR-525 $(4.73 \mathrm{ml})$ (table 1). The volume required to tip the bucket was calculated as:

$$
\mathrm{V}_{\text {tip }}(\mathrm{ml})=0.0254 \mathrm{~cm} \times\left(\pi \times \mathrm{D}^{2}\right) / 4
$$

where, $\mathrm{D}$ is collecting diameter of the rain gauge, $\mathrm{cm}$.

If the measured $\mathrm{V}_{\text {tip }}$ for a TBR was not equal to the $\mathrm{V}_{\text {tip }}$ calculated from equation 1, the calibration screws below the tipping bucket mechanism were adjusted such that each bucket tipped at a volume $\left(\mathrm{V}_{\text {tip }}\right)$, equivalent to $0.254 \mathrm{~mm}$ of rainfall.

A peristaltic pump (Masterflex, Inc., Vernon Hills, IL, USA) was used to generate a range of flow rates that simulated different rainfall intensities. The peristaltic pump was calibrated for consistent discharge over a range of flow rates. The pump discharge at each flow rate was measured in two replications of $10+$ readings at $30 \mathrm{sec}$ intervals using a graduated cylinder and a stop-watch. Following pump calibration, dynamic calibration of each TBR was conducted by subjecting the TBRs to a range of constant flow rates simulated by the pump system. Different flow rates were obtained by changing pump speed and/or the size of tubing. A constant water head was maintained at the pump inlet during the experiment in order to achieve constant pump discharge. The pump flow rates were measured and recorded as true rainfall rates. At each rainfall rate, after the TBR reached steady operating conditions, data were recorded for a minimum of 20 min using the CR-10 (Campbell Scientific, Logan, Utah) datalogger. The pulse inputs created by the tipping bucket mechanism were recorded by the CR-10 data-logger at 1-min intervals. Raw data collected in the form of number of tips per minute were then converted into corresponding rainfall depth (0.254 mm per tip) and cumulative volumetric depths. This procedure was repeated over a range of flow rates (i.e., rainfall intensities) starting from 12.5 to $230 \mathrm{~mm} \mathrm{~h}^{-1}$. This part of dynamic calibration helped estimate the under catchment errors when the TBRs are set at their nominal volumetric setting (equivalent to 0.254 mm per tip).

In order to assess the effect of change in volumetric calibration, the volumes per tip of TBRs were further adjusted to be $10 \%$ to $15 \%$ less and greater than their nominal volumes, respectively. Dynamic calibration was 
conducted at each of these two additional volumetric settings for each TBR model, using the same methodology and experimental set up described above.

\subsection{FIELD EXPERIMENT AND DATA}

Following the laboratory assessment, the three TBRs were installed in the field alongside a standard nonrecording gauge (SNRG) at the Waterman Agricultural and Natural Resources Laboratory (WANRL) of the Ohio State University in Columbus Ohio. Data were collected from June 2011 to July 2012. Furthermore, data recorded by a TBR model HS-TB3 and an adjacent SNRG set in the USDA-ARS Riesel Watershed (Riesel, TX, USA) during January through May of 2002 were used to validate and compare the statistical models developed for HS-TB3 (Harmel et al. 2003; 2014).

\subsection{Data ANALysis}

\subsubsection{Tests for evaluating consistency and accuracy of pump}

The consistency of the peristaltic pump over a range of flow rates was determined by analyzing a total of 87 flow rates. Average of repeated measurements at each flow rate was considered as the expected (true) flow rate. Then, the difference between each measurement and the average value was used to calculate percent deviation with respect to the sample average. A 1-sample t-test was used to test the null hypothesis that the mean of percent deviation for all flow rates was equal to zero; and the alternative hypothesis of inequality. Furthermore, $95 \%$ confidence intervals were calculated for the percent deviation. A one-way ANOVA was performed to test the equality of means for the percent deviations calculated for all 87 flow rates $(\mathrm{DF}=85)$ at a significance level $(\alpha)$ of 0.05 . All statistical analyses were conducted with Minitab (ver. 16) statistical software (Minitab Inc. 2013).

\subsubsection{Tests for estimating errors of TBRs}

The first step of dynamic calibration was to estimate the percent error associated with TBR measurements. Percent errors in measured intensities were calculated with respect to actual intensities (pump flow rates considered as 'actual' intensities). A one-way ANOVA was performed to test the equality of means for the percent errors at a significance level $(\alpha)$ of 0.05 . Plotting measured vs. actual rainfall provides a visual representation of errors in the TBR measurements so that the slope of the regression line indicates the deviation of the measured values from the actual. This deviation is proportional to the scale, i.e., the greater the magnitude, the greater the error in measurement. The intercept of the regression line is equivalent to the constant error that is independent of the 
magnitude. Thus, the intercept may form a greater percentage of total error in measurement at lower magnitudes; and becomes less important at greater magnitudes.

\subsubsection{Statistical models for correcting TBR collected data}

Developing statistical and/or mathematical models for correcting measurements of TBRs is the second step of dynamic calibration. The following statistical models and approaches were selected for all three TBR models:

\subsubsection{Simple linear regression model for intensity correction:}

A simple linear regression was used to establish a relationship between the measured rainfall intensities and the actual intensities generated by the peristaltic pump. Simple linear regression equations were developed, such that actual rainfall intensity was a linear function of measured rainfall intensity for each combination of TBR model and time period. The three TBR models, three volumetric calibration approaches, and five different time periods created 45 different combinations, and hence 45 regression equations. The slopes of regression equations were compared with each other and with a slope value of 1 for using an Analysis of Covariance (ANCOVA) test (Wildt and Ahtola, 1978) in Minitab. The significance was tested at a probability level $(\alpha)$ of 0.05 . An intercept value represents actual intensity of rainfall corresponding to measured rainfall intensity of zero, which in turn represents no rainfall. Thus, any positive or negative value of actual rainfall intensity corresponding to zero measured intensity is practically impossible. Therefore, intercept was assumed to be zero for all the regression equations in order to better represent the relationship between the actual and measured rainfall intensities. The coefficient of determination $\left(\mathrm{R}^{2}\right)$, and mean and standard deviation of residual error were used as indicators of goodness of fit for each regression model. These simple linear regression models are referred as 'intensity curve-based slope method' in this manuscript.

\subsubsection{T vs. 1/Q model for intensity correction:}

Regression equations were developed for time between tips (T) as a function of the inverse of flow rate $\left(\mathrm{i}_{\mathrm{a}}^{-1}\right)$. Values of T were calculated as:

$$
\mathrm{T}=\Delta \mathrm{t} / \mathrm{n}
$$

where,

$\Delta \mathrm{t}=$ time interval selected for analysis, $\Delta \mathrm{t}=1,2,5,10$ and $20 \mathrm{~min}$, respectively, and

$\mathrm{n}=$ number of tips recorded in time interval, $\Delta \mathrm{t}$.

Values of $\mathrm{T}$, thus calculated, were regressed against $\mathrm{i}_{\mathrm{a}}{ }^{-1}$ to obtain a simple linear regression equation as follows:

$$
\mathrm{i}_{\mathrm{a}}=\mathrm{V}_{\text {tip }} /(\mathrm{T}-\mathrm{t})
$$




$$
\text { i.e., } \mathrm{T}=\mathrm{V}_{\text {tip }}\left(1 / \mathrm{i}_{\mathrm{a}}\right)+\mathrm{t}
$$

where,

$\mathrm{i}_{\mathrm{a}}$ is the actual flow rate (simulated rainfall intensity),

$t$ is the intercept of regression equation suggesting tipping time (time for bucket to move from rest to the position at which the central bucket division is beneath the inlet funnel tip), and

$\mathrm{V}_{\text {tip }}$ is slope of regression equation indicating bucket volume.

With time-of-tip data recorded from each TBR, the time between consecutive tips (T) can be calculated. Then actual rainfall intensities $\left(i_{a}\right)$ can be calculated for each value of $T$ by plugging values of $V_{\text {tip }}$ and $t$ into equation 3 . The actual depths of rainfall can then be calculated simply by multiplying the actual intensity ( $i_{a}$ ) by time interval (T). The coefficient of determination $\left(\mathrm{R}^{2}\right)$, and mean and standard deviation of residual error were used as indicators of goodness of fit for each linearized regression model from equation 4. These regression models are referred as ' $\mathrm{T}$ vs. 1/Q models' in this manuscript.

\subsubsection{Quadratic model for intensity and depth correction:}

A quadratic model as suggested by Costello and Williams (1991) was developed for each TBR using the equivalent rainfall depth $(\mathrm{mm})$ per tip plotted against corresponding actual intensities $\left(\mathrm{mm} \mathrm{h}^{-1}\right)$ for different time intervals $(1,2,5,10$ and $20 \mathrm{~min})$. At any given time interval, the depth per tip was calculated as:

$$
\mathrm{V}_{\text {tip }}(\mathrm{i})=\mathrm{i}_{\mathrm{a}} * \Delta \mathrm{t} / \mathrm{n}=\mathrm{R}_{\Delta \mathrm{t}} / \mathrm{n}
$$

where,

$\mathrm{V}_{\text {tip }}(\mathrm{i})$ is the equivalent rainfall depth per tip (mm),

$\mathrm{i}_{\mathrm{a}}$ is the actual rainfall intensity $\left(\mathrm{mm} \mathrm{h}^{-1}\right)$,

$\Delta \mathrm{t}$ is time interval selected for analysis, $\Delta \mathrm{t}=1,2,5,10$ and 20 min respectively,

$\mathrm{n}$ is number of tips recorded in time interval $\Delta \mathrm{t}$, and

$\mathrm{R}_{\Delta \mathrm{t}}$ is the actual volumetric depth (mm).

A quadratic model was then fitted to the data using multiple linear regressions, such that:

$$
\mathrm{V}_{\text {tip }}(\mathrm{i})=\mathrm{b}_{0}+\mathrm{b}_{1} \mathrm{i}_{\mathrm{m}}+\mathrm{b}_{2} \mathrm{i}_{\mathrm{m}}{ }^{2}
$$

where,

$\mathrm{i}_{\mathrm{m}}$ is the measured rainfall intensity $\left(\mathrm{mm} \mathrm{h}^{-1}\right)$ 
The calibration parameters $b_{0}, b_{1}$, and $b_{2}$ were derived for each TBR model at three different volumetric settings (table 1). The slopes of regression equations were compared with each other and with a slope value of 1 for using an Analysis of Covariance (ANCOVA) test (Wildt and Ahtola, 1978) in Minitab. The significance was tested at a probability level $(\alpha)$ of 0.05 . The coefficient of determination $\left(\mathrm{R}^{2}\right)$, and mean and standard deviation of residual error were used as indicators of goodness of fit for each multiple regression model. The rainfall data recorded using fixed time interval $(\Delta t)$, can be corrected as follows:

Calculate the measured intensities $\left(i_{m}\right)$ for each time interval $(\Delta t)$ as:

$$
\mathrm{i}_{\mathrm{m}}=\mathrm{n} * \mathrm{~V}_{\mathrm{tip}} / \Delta \mathrm{t}
$$

and, the actual depth of rainfall can then be calculated as:

$$
\mathrm{D}=\mathrm{n} *\left(\mathrm{~b}_{0}+\mathrm{b}_{1} \mathrm{i}_{\mathrm{m}}+\mathrm{b}_{2} \mathrm{i}_{\mathrm{m}}{ }^{2}\right)
$$

The rainfall data recorded by TBRs using the 'time-of-tip' method can be corrected as follows: Calculate the time interval between consecutive tips $(\mathrm{T})$ from the recorded measurements. For each $\mathrm{T}(\mathrm{h})$, the actual depth of rainfall $(\mathrm{mm})$ can then be directly calculated using equation 9.

$$
D=T\left\{\frac{-\left(b_{1}-T\right)-\left[\left(b_{1}-T\right)^{2}-4 b_{2} b_{0}\right]^{1 / 2}}{2 b_{2}}\right\}
$$

\subsubsection{Adjusting the volumetric calibration for minimal measurement errors:}

The results from dynamic calibration were used to select and/or derive a volumetric setting for each TBR that may help minimize the measurement errors and eliminate the need for post-processing of rainfall data. The relationship between coefficients of intensity curves and volumetric calibration for each TBR was used to obtain the optimum volumetric setting for the corresponding TBR. Furthermore, for deriving the optimum volumetric calibration, an approach suggested by Marsalek (1981) was adopted as follows:

Time elapsed between two tips, T, can be expressed as:

$$
\mathrm{T}=\mathrm{t}_{\mathrm{f}}+\mathrm{t}
$$

where, $\mathrm{t}$ is the tipping time (time for the bucket to move from rest to the position at which the central bucket division is beneath the inlet funnel tip), and $t_{\mathrm{f}}$ is the duration of the bucket filling, and can be given by:

$$
\mathrm{t}_{\mathrm{f}}=\left(\mathrm{V}_{\text {tip }}-\Delta \mathrm{V}\right) / \mathrm{Q}=(\mathrm{r}-\Delta \mathrm{h}) / \mathrm{i}_{\mathrm{a}}
$$

The recorded intensity $\left(\mathrm{i}_{\mathrm{m}}\right)$ can be expressed as:

$$
\mathrm{i}_{\mathrm{m}}=\mathrm{r} / \mathrm{T}
$$


where, $\Delta \mathrm{V}(\mathrm{ml})$ and $\Delta \mathrm{h}(\mathrm{mm})$ are the reductions in the nominal bucket volume $\left(\mathrm{V}_{\text {tip }}, \mathrm{ml}\right)$ and in the corresponding depth per tip (r, mm), respectively, $Q$ is the actual flow rate $\left(\mathrm{ml} \mathrm{h}^{-1}\right)$, and $i_{a}$ is the actual rainfall intensity $\left(\mathrm{mm} \mathrm{h}^{-1}\right)$.

After substituting equations 10 and 11 into equation 12:

$$
\left(\mathrm{i}_{\mathrm{m}} / \mathrm{i}_{\mathrm{a}}\right)=(\mathrm{r}) /\left(\mathrm{r}-\Delta \mathrm{h}+\mathrm{t} * \mathrm{i}_{\mathrm{a}}\right)
$$

Equation 13 implies that if $\Delta \mathrm{h}=\mathrm{t} * \mathrm{i}_{\mathrm{a}}$, then $\mathrm{i}_{\mathrm{m}}=\mathrm{i}_{\mathrm{a}}$. Thus, it is possible to select a reference intensity and the corresponding value of $\Delta \mathrm{h}$ for which the recorded intensity will equal the actual intensity. For actual intensities smaller than the reference value, the recorded intensities would exceed the actual intensities, but by a lesser amount than in the case where bucket volume is set to correspond to the nominal rainfall depth increment per tip.

\subsection{VALIDATION OF STATISTICAL MODELS FOR CORRECTION OF FIELD DATA}

Field collected rainfall data were used to validate the statistical models developed during the dynamic calibration. Corrections were applied to rainfall data collected by each TBR using the three statistical models, and corrected data were compared with measurements from an adjacent SNRG. The performance of statistical models was evaluated visually by plotting the individual and cumulative values of uncorrected, corrected, and SNRG measured rainfall data. The models were further evaluated on the basis of change in average deviation of TBR measurements before and after correction with respect to corresponding rainfall measurements of the SNRG.

\section{RESULTS}

\subsection{Volumetric Calibration}

Volumetric calibration of TBRs proved to be an important step before conducting the experiment. The nominal volume of water required for one bucket tip (equivalent to $0.254 \mathrm{~mm}$ ) was found to be $4.73 \mathrm{ml}$ for TR-525 and 8.24 $\mathrm{ml}$ for both ISCO-674 and HS-TB3 (table 1). The calibration screws at the bottom of the tipping bucket mechanism in each TBR were adjusted for the desired volumes, such that one tip represented $0.254 \mathrm{~mm}$ (0.01 in) of rainfall. Each TBR model was also adjusted volumetrically such that both buckets tip at the same volume per tip. For example, model HS-TB3 had to be adjusted from $7.5 \mathrm{ml} \mathrm{tip}^{-1}$ to $8.24 \mathrm{ml} \mathrm{tip}^{-1}$ of each bucket.

\subsection{Pump Calibration}

A cumulative distribution function (CDF) for percent deviations of flow rates generated by the peristaltic pump from their respective means and an empirical CDF fitted based on parameters (mean and standard deviation) estimated from the sample were compared. The CDF indicated that the percent deviation data were normally 
distributed and that most of the data fell in the range of $\pm 5 \%$ of mean percent deviation. The mean, median and standard deviation of percent deviations were $-0.0001,-0.0015$, and 2.3 , respectively. These parameters suggest very high reliability in the consistency of flow rates generated by the peristaltic pump. A one-sample t-test indicated that the mean of percent deviations is not equal to zero with $\mathrm{p}=0.999(\alpha=0.05, \mathrm{~N}=953)$. The $95 \%$ confidence interval of the mean of percent deviations was $(-0.147$ to +0.146$)$. In other words, the error associated with the deviation in pump discharge was very small $( \pm 0.15 \%$ at $95 \%$ confidence level $)$. A one-way ANOVA for percent deviations was conducted to test the quality of means of percent deviations at the 0.05 significance level. A p-value of 1.0 indicated that the null hypothesis of equal means cannot be rejected, i.e., there is no sufficient evidence to reject the hypothesis that the means are equal. This indicates the consistency of pump discharges over the entire range of flow rates. Although, the means of percent deviations were close to zero $( \pm 0.15 \%$ at $95 \%$ confidence level $)$, the variability of pump flow was slightly high (standard deviation of $\sim 5.3 \%$ ) at lower flow rates $\left(<3.5 \mathrm{~cm} \mathrm{~h}^{-1}\right)$ than the variability at higher $\left(>3.5 \mathrm{~cm} \mathrm{~h}^{-1}\right.$ ) flow rates (standard deviation of $\sim 2 \%$ ).

\subsection{DYNAMiC CalibRation}

The results of dynamic calibration are summarized in following subsections that discuss: errors in TBR measurements, statistical models to correct the TBR measurements, and lastly optimizing the dynamic and volumetric calibration for minimal measurement errors.

\subsubsection{Measurement errors of TBRs set at different volumetric calibrations}

Dynamic calibration showed that when TBRs were set at (or close to) their nominal volumetric settings, the measurements errors were negative at all flow rates (except model ISCO, at $5 \mathrm{~cm} \mathrm{hr}^{-1}$ ), suggesting a tendency to underestimate (fig. 2) 

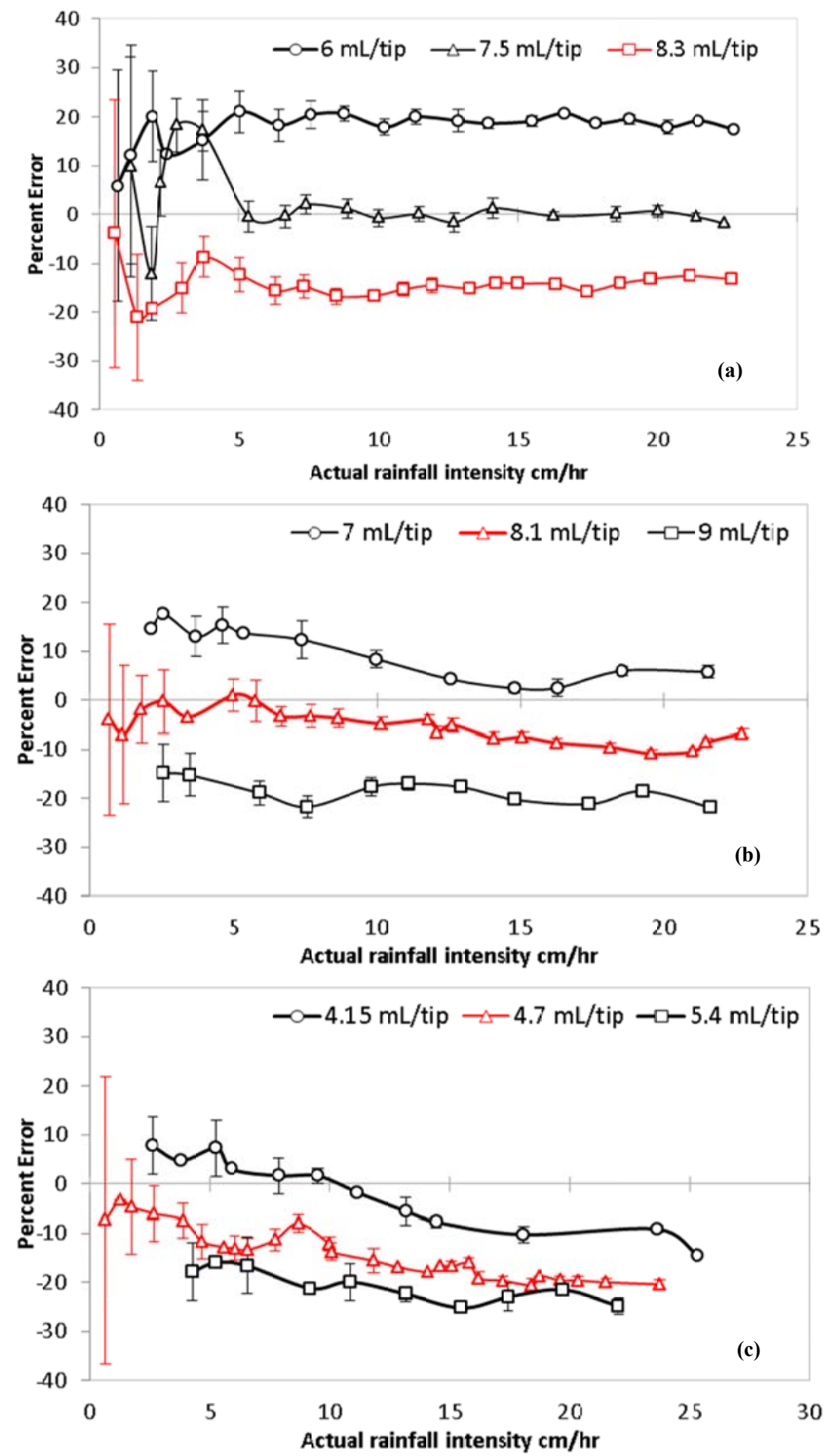

Fig. 2 Percent error in intensities measured by three TBR models at different volumetric settings (a) Model HS-TB3 (b) Model ISCO-675 (c) Model TR-525.

(Red line represents performance of the TBR model set or close to nominal volumetric calibration. The marker symbol represents mean percent error and the error bars represent standard deviation of the percent error at given rainfall intensity. Errors were calculated based on 5-minute totals obtained from 1-minute measurements of TBRs) 
Model TR-525, set at nominal volume of $4.7 \mathrm{ml} \mathrm{tip}^{-1}$ showed the greatest underestimation errors (up to $54 \%$ ) in the measured intensities, followed by HS-TB3 (up to 45\%) and ISCO-674 (up to 22\%), respectively. The average percent errors in measurements of the TBR models set at their respective nominal volumetric settings were $-14.2 \%$ for TR-525 and HS-TB3, and $-5.3 \%$ for ISCO-674 (table 2). In general, the variation in measurement errors was greater at low flow rates, and decreased from less to greater flow rates. Models TR-525 and ISCO-674 showed increasing underestimation errors at greater intensities, while model HS-TB3 showed relatively uniform errors across all flow rates.

Table 2 Summary statistics for percent errors in TBR measurements of rainfall intensities $\uparrow$ as compared to actual flow rates

\begin{tabular}{|c|c|c|c|c|c|c|c|c|c|}
\hline & \multicolumn{3}{|c|}{ HS-TB3 } & \multicolumn{3}{|c|}{ ISCO-674 } & \multicolumn{3}{|c|}{ TR-525 } \\
\hline & $6 \mathrm{ml}$ tip $^{-1}$ & $7.5 \mathrm{ml} \mathrm{tip}^{-1}$ & $* 8.3 \mathrm{ml} \mathrm{tip}^{-1}$ & $7 \mathrm{ml} \mathrm{tip}^{-1}$ & $* 8.1 \mathrm{ml} \mathrm{tip}^{-1}$ & $9 \mathrm{ml} \mathrm{tip}^{-1}$ & $4.15 \mathrm{ml} \mathrm{tip}^{-1}$ & $* 4.7 \mathrm{ml} \mathrm{tip}^{-1}$ & $5.4 \mathrm{ml} \mathrm{tip}^{-1}$ \\
\hline Average: & $17.8^{\mathrm{a} 1}$ & $2.2^{\mathrm{b} 1}$ & $-14.2^{\mathrm{cl}}$ & $9.7^{\mathrm{a} 2}$ & $-5.3^{\mathrm{b2}}$ & $-18.6^{\mathrm{c} 2}$ & $-1.9^{\mathrm{a3}}$ & $-14.2^{\mathrm{b} 3}$ & $-20.9^{\mathrm{c} 3}$ \\
\hline Std. Dev. & 7.9 & 8.7 & 6.9 & 5.6 & 6.2 & 3.3 & 7.6 & 8.3 & 3.6 \\
\hline Minimum & -19.8 & -17.6 & -45.1 & 0.9 & -22.5 & -23.7 & -14.5 & -53.7 & -27.2 \\
\hline Q1 & 16.8 & -1.3 & -16.5 & 4.7 & -8.7 & -21.2 & -8.86 & -19.0 & -23.2 \\
\hline Median & 18.7 & 0.7 & -14.1 & 8.7 & -6.1 & -18.4 & -1.8 & -15.6 & -21.2 \\
\hline Q3 & 20.9 & 3.1 & -12.9 & 14.6 & -3.4 & -17.6 & 4.52 & -11.6 & -18.6 \\
\hline Maximum & 41.2 & 37.3 & 9.8 & 18.7 & 31.0 & -5.9 & 16.5 & 39.0 & -13.0 \\
\hline $\mathbf{N}$ & 90 & 71 & 85 & 48 & 109 & 44 & 48 & 125 & 40 \\
\hline
\end{tabular}

$\dagger$ Measured intensities based on 5-minute totals obtained from 1-minute measurements.

*Represents the nominal (theoretical) volumetric calibration of TBR

$\ddagger$ For each TBR model, $\%$ error values followed by same letter indicate that the means are not significantly different from each other ( $\alpha=0.05)$

Std. Dev. = Standard deviation, $\mathrm{Q} 1=$ First quartile, $\mathrm{Q} 3=$ Third quartile, $\mathrm{N}=$ Sample size

Changing volumetric calibration significantly affected the trends of measurement errors $(\alpha=0.05)$ in all TBR models (fig. 2 and table 2). In the case of ISCO-674 and TR-525 when the volume per tip was increased from their nominal volumetric settings, the average percent errors became more negative $(-5.3 \%$ to $-18.6 \%$ for ISCO-674, and $14.2 \%$ to $-20.9 \%$ for TR-525). Conversely, when the volume per tip was decreased below the nominal volumetric setting for each TBRs, the average percent errors became more positive $(-14.2 \%$ to $2.2 \%$ for HS-TB3, $-5.3 \%$ to $9.7 \%$ for ISCO- 674 , and $-14.2 \%$ to $-1.9 \%$ for TR-525). In the case of HS-TB3, both volumetric settings were less than the nominal volume. At $7.5 \mathrm{ml} \mathrm{tip}^{-1}$, the calculated errors in HS-TB3 measurements were consistently close to zero across all rainfall intensities except at some low flow rates (less than $4 \mathrm{~cm} \mathrm{~h}^{-1}$ ). When the volumetric calibration was set at $6 \mathrm{ml} \mathrm{tip}^{-1}$, the measurement errors seemed to reverse in sign compared to those at nominal volume per tip. Model TR-525 always resulted in negative measurement errors (suggesting underestimation), even after setting the rain gauge at the lowest possible volumetric setting (i.e., $4.15 \mathrm{ml} \mathrm{tip}^{-1}$ ). 
In general, when the TBRs were set at their respective nominal volumes, they tended to underestimate the actual rainfall (resulting in negative measurement errors). At greater than nominal volumes, the TBRs further underestimate the actual flow rates (resulting in more negative measurement errors). Conversely, at lower than nominal volume, the TBRs tend to overestimate the flow rates (resulting in positive measurement errors) (fig. 2 and table 2).

\subsubsection{Statistical models for correcting TBR measurements}

\subsubsection{Simple linear regression equations for intensity corrections:}

Simple linear regression equations derived for actual rainfall intensities (i.e., pump flow rates) as functions of measured intensities (calculated at 1, 2, 5, 10 and 20 min time intervals) were summarized by their coefficients (i.e., slope value), corresponding $\mathrm{R}^{2}$ values, and average residual errors (table 3). Time interval seemed to affect the magnitude of slope. However, the time interval effects were not statistically significant $(\alpha=0.05)$ for any of the TBR models. Therefore, a single regression equation based on average values of coefficients was developed for each TBR model. With $\mathrm{R}^{2}$ (coefficient of determination) values above 0.98 , the regression equations showed good agreement between the actual and measured values of intensities for all three TBRs (table 3). In general, the mean residual errors were highest in case of TR-525, followed by ISCO-674 and HS-TB3, respectively. At any given time interval, the coefficients developed for different volumetric calibrations of the same TBR were significantly different from each other $(\alpha=0.05)$ (table 3$)$, suggesting that the equations are sensitive to changes in volumetric calibration of TBRs. 
Table 3 Calibration Parameters (Slope, m) for intensity curves (actual vs. measured rainfall Intensities)

\begin{tabular}{|c|c|c|c|c|c|c|c|c|c|}
\hline \multirow{3}{*}{$\frac{V_{\text {tip }} \mathrm{ml} \mathrm{tip}^{-1} \rightarrow}{\text { time interval }}$} & \multicolumn{9}{|c|}{ HS-TB3 } \\
\hline & \multicolumn{3}{|c|}{6} & \multicolumn{3}{|c|}{7.5} & \multicolumn{3}{|c|}{8.3} \\
\hline & $\mathbf{m}^{[\dagger]}$ & $\mathbf{R}^{2}$ & $\mathrm{RE} \pm \mathrm{SD}$ & m & $\mathbf{R}^{2}$ & $\mathrm{RE} \pm \mathrm{SD}$ & $\mathbf{m}$ & $\mathbf{R}^{2}$ & ${ }^{\S} \mathrm{RE} \pm \mathrm{SD}$ \\
\hline $1^{[\#]}$ & $0.8381 \mathrm{a}$ & 0.9883 & $0.45 \pm 7.53$ & $0.9977 \mathrm{~b}$ & 0.9863 & $-0.31 \pm 8.09$ & $1.1586 \mathrm{c}$ & 0.9856 & $0.71 \pm 8.09$ \\
\hline 2 & $0.8401 \mathrm{a}$ & 0.9964 & $0.18 \pm 4.17$ & $1.0003 b$ & 0.9951 & $-0.58 \pm 4.84$ & $1.1604 \mathrm{c}$ & 0.9962 & $0.41 \pm 4.17$ \\
\hline 5 & $0.8405 \mathrm{a}$ & 0.9993 & $0.03 \pm 1.84$ & $1.0009 \mathrm{~b}$ & 0.9982 & $-0.62 \pm 2.89$ & $1.1625 \mathrm{c}$ & 0.9988 & $0.32 \pm 2.28$ \\
\hline 10 & $0.8406 \mathrm{a}$ & 0.9996 & $0.03 \pm 1.42$ & $1.0011 \mathrm{~b}$ & 0.9986 & $-0.64 \pm 2.54$ & $1.1623 \mathrm{c}$ & 0.9992 & $0.29 \pm 1.86$ \\
\hline 20 & $0.8406 \mathrm{a}$ & 0.9997 & $0.03 \pm 1.29$ & $1.001 \mathrm{~b}$ & 0.9987 & $-0.75 \pm 2.37$ & $1.1624 \mathrm{c}$ & 0.9993 & $0.29 \pm 1.79$ \\
\hline \multirow[t]{2}{*}{ Average $^{[\ddagger]}$} & $0.8400^{*}$ & & & 1.0002 & & & $1.1612 *$ & & \\
\hline & \multicolumn{9}{|c|}{ ISCO-674 } \\
\hline $\mathrm{V}_{\text {tip }} \mathrm{ml} \mathrm{tip}^{-1} \rightarrow$ & \multicolumn{3}{|c|}{7} & \multicolumn{3}{|c|}{8.1} & \multicolumn{3}{|c|}{9} \\
\hline time interval & $\mathbf{m}$ & $\mathbf{R}^{2}$ & $\mathrm{RE} \pm \mathrm{SD}$ & $\mathbf{m}$ & $\mathbf{R}^{2}$ & $\mathrm{RE} \pm \mathrm{SD}$ & $\mathbf{m}$ & $\mathbf{R}^{2}$ & $\mathbf{R E} \pm \mathrm{SD}$ \\
\hline 1 & $0.9449 a$ & 0.9889 & $-1.12 \pm 12.7$ & $1.0800 \mathrm{~b}$ & 0.9873 & $-0.61 \pm 7.8$ & $1.2430 \mathrm{c}$ & 0.9846 & $3.32 \pm 16.4$ \\
\hline 2 & $0.9468 \mathrm{a}$ & 0.9958 & $-1.1 \pm 4.00$ & $1.0823 b$ & 0.9954 & $-0.9 \pm 4.63$ & $1.2454 \mathrm{c}$ & 0.9933 & $-0.45 \pm 4.94$ \\
\hline 5 & $0.9471 \mathrm{a}$ & 0.9968 & $-1.13 \pm 3.46$ & $1.0831 \mathrm{~b}$ & 0.9973 & $-0.94 \pm 3.46$ & $1.2463 \mathrm{c}$ & 0.9969 & $-0.54 \pm 3.34$ \\
\hline 10 & $0.9473 a$ & 0.9973 & $-1.14 \pm 3.18$ & $1.0843 b$ & 0.9976 & $-1.01 \pm 3.31$ & $1.2465 \mathrm{c}$ & 0.9975 & $-0.55 \pm 3.02$ \\
\hline 20 & $0.9473 a$ & 0.9973 & $-1.14 \pm 3.22$ & $1.0844 \mathrm{~b}$ & 0.9976 & $-1.02 \pm 3.31$ & $1.2465 \mathrm{c}$ & 0.9976 & $-0.56 \pm 3.02$ \\
\hline \multirow[t]{2}{*}{ Average $^{[t]}$} & $0.9467^{*}$ & & & $1.0828^{*}$ & & & $1.2455^{*}$ & & \\
\hline & \multicolumn{9}{|c|}{ TR-525 } \\
\hline $\mathrm{V}_{\text {tip }} \mathrm{ml} \mathrm{tip}^{-1} \rightarrow$ & \multicolumn{3}{|c|}{4.15} & \multicolumn{3}{|c|}{4.7} & \multicolumn{3}{|c|}{5.4} \\
\hline time interval & $\mathbf{m}$ & $\mathbf{R}^{2}$ & $\mathrm{RE} \pm \mathrm{SD}$ & $\mathbf{m}$ & $\mathbf{R}^{2}$ & $\mathrm{RE} \pm \mathrm{SD}$ & $\mathbf{m}$ & $\mathbf{R}^{2}$ & $\mathbf{R E} \pm \mathrm{SD}$ \\
\hline 1 & $1.0891 \mathrm{a}$ & 0.9774 & $-2.73 \pm 10.44$ & $1.2169 \mathrm{~b}$ & 0.9826 & $-1.16 \pm 8.98$ & $1.2904 \mathrm{c}$ & 0.9754 & $-0.62 \pm 9.21$ \\
\hline 2 & $1.0912 \mathrm{a}$ & 0.9844 & $-2.96 \pm 8.50$ & $1.2197 \mathrm{~b}$ & 0.9925 & $-1.43 \pm 5.76$ & $1.2935 \mathrm{c}$ & 0.9886 & $-0.13 \pm 6.48$ \\
\hline 5 & $1.0920 \mathrm{a}$ & 0.9872 & $-3.05 \pm 7.61$ & $1.2225 \mathrm{~b}$ & 0.9954 & $-1.51 \pm 4.47$ & $1.2949 \mathrm{c}$ & 0.9943 & $-1.06 \pm 4.36$ \\
\hline 10 & $1.0922 \mathrm{a}$ & 0.9877 & $-3.07 \pm 7.49$ & $1.2207 \mathrm{~b}$ & 0.9956 & $-1.53 \pm 4.31$ & $1.2951 \mathrm{c}$ & 0.9955 & $-1.08 \pm 3.89$ \\
\hline 20 & $1.0922 \mathrm{a}$ & 0.9879 & $-3.08 \pm 7.58$ & $1.2197 \mathrm{~b}$ & 0.9954 & $-1.55 \pm 4.33$ & $1.2952 \mathrm{c}$ & 0.9957 & $-1.09 \pm 3.9$ \\
\hline Average $^{|*|}$ & $1.0913^{*}$ & & & $1.2199^{*}$ & & & $1.2938 *$ & & \\
\hline
\end{tabular}

[ $\dagger$ C Coefficients with the same letter in a column are not significantly different from each other (Tukey-Kramer test, $\alpha=0.05$ )

$[\S] \mathrm{RE}=$ Mean residual error, $\mathrm{SD}=$ standard deviation of residual error

[\#] Different letters followed by coefficients in a row indicate that coefficients are significantly different from each other (Tukey-Kramer test, $\alpha=0.05$ )

[†] Coefficients with * are significantly different from value of 1 (Tukey-Kramer test, $\alpha=0.05$ )

A slope $(\mathrm{m})$ value of 1 suggests zero error in TBR measurements. A slope value less than 1 suggests overestimation; and a slope value greater than 1 suggests underestimation. 


\subsubsection{T vs. 1/Q model for intensity correction:}

After plotting the values of $\mathrm{T}$ as functions of the inverse of flow rates $\left(\mathrm{i}_{\mathrm{a}}{ }^{-1}\right)$ as described by Calder and Kidd (1978), the slopes of regression equations represented volume per tip ( $\mathrm{mm} \mathrm{tip}^{-1}$ or $\left.\mathrm{ml} \mathrm{tip}^{-1}\right)$ and intercepts represented tipping time $\left(\mathrm{sec} \mathrm{tip}^{-1}\right.$ ) for the respective TBRs (table 4). This approach did not give realistic results initially, and resulted in unreasonably small or large estimates of $t$ and $\mathrm{V}_{\text {tip }}$. An analysis of the theoretical basis for this approach revealed that the T vs. 1/Q model is more suitable for TBR data collected using "time of tip" method, data at higher rainfall intensities, and data recorded at longer time intervals. Therefore, a new set of equations was developed after filtering the experimental data for higher rainfall intensities, and longer time intervals that resulted in more realistic estimates of $t$ and $V_{\text {tip }}$ (table 4). With $\mathrm{R}^{2}$ values above 0.98 , all the regression equations were able to explain most of the variance in values of $\mathrm{T}$ corresponding to changes in $\mathrm{ia}^{-1}$. The mean standard errors for all the regression models were of the order of $10^{-15}$ to $10^{-16} \mathrm{sec}$, with relatively large standard deviations (of the order of $10^{-}$

${ }^{2} \mathrm{sec}$ ). The mean standard errors of regression models had the greatest standard deviations for model TR-525, followed by those for ISCO-674 and HS-TB3 respectively.

Table 4 Calibration parameters for $T$ vs. 1/Q model

\begin{tabular}{|c|c|c|c|c|c|c|}
\hline TBR model & $\begin{array}{c}\text { Actual } V_{\text {tip }} \\
\mathrm{ml} \mathrm{tip}^{-1}\left(\mathrm{~mm} \mathrm{tip}^{-1}\right)\end{array}$ & $\begin{array}{c}\text { Time } \\
\text { interval } \\
\text { min }\end{array}$ & $\begin{array}{c}\text { Slope } \\
\left.\text { (Calculated } V_{\text {tip }}\right) \\
\text { mm tip }\end{array}$ & $\begin{array}{c}\text { Intercept } \\
\text { (Calculated t) } \\
\text { sec }\end{array}$ & $\mathbf{R}^{2}$ & $* \mathbf{R E} \pm \mathbf{S D}$ \\
\hline \multirow{9}{*}{ HS-TB3 } & \multirow{3}{*}{$6.0(0.185)$} & 5 & 0.2000 & 0.2500 & 0.9925 & $-1.4 \mathrm{E}-15 \pm 0.0350$ \\
\hline & & 10 & 0.1991 & 0.2632 & 0.9952 & $-5.9 \mathrm{E}-16 \pm 0.0285$ \\
\hline & & 20 & 0.1991 & 0.2632 & 0.9964 & $-9.6 \mathrm{E}-16 \pm 0.0259$ \\
\hline & \multirow{3}{*}{$7.5(0.231)$} & 5 & 0.2431 & 0.2144 & 0.9926 & $-2.1 \mathrm{E}-15 \pm 0.0703$ \\
\hline & & 10 & 0.2429 & 0.2170 & 0.9974 & $-7.4 \mathrm{E}-17 \pm 0.0423$ \\
\hline & & 20 & 0.2429 & 0.2171 & 0.9984 & $-1.2 \mathrm{E}-15 \pm 0.0350$ \\
\hline & \multirow{3}{*}{$8.3(0.256)$} & 5 & 0.2865 & 0.2249 & 0.9900 & $-1.0 \mathrm{E}-15 \pm 0.0649$ \\
\hline & & 10 & 0.2866 & 0.2235 & 0.9942 & $-1.2 \mathrm{E}-15 \pm 0.0509$ \\
\hline & & 20 & 0.2866 & 0.2236 & 0.9956 & $1.2 \mathrm{E}-15 \pm 0.0469$ \\
\hline \multirow{9}{*}{ ISCO-674 } & \multirow{3}{*}{$7.0(0.216)$} & 5 & 0.2238 & 0.4761 & 0.9898 & $4.4 \mathrm{E}-17 \pm 0.1358$ \\
\hline & & 10 & 0.2283 & 0.3730 & 0.9906 & $-1.4 \mathrm{E}-15 \pm 0.1193$ \\
\hline & & 20 & 0.2303 & 0.2827 & 0.9933 & $-1.6 \mathrm{E}-15 \pm 0.1316$ \\
\hline & \multirow{3}{*}{$8.1(0.250)$} & 5 & 0.2592 & 0.3629 & 0.9933 & $9.4 \mathrm{E}-16 \pm 0.1020$ \\
\hline & & 10 & 0.2577 & 0.3986 & 0.9946 & $-2.7 \mathrm{E}-15 \pm 0.0924$ \\
\hline & & 20 & 0.2577 & 0.3986 & 0.9951 & $1.8 \mathrm{E}-16 \pm 0.0903$ \\
\hline & \multirow{3}{*}{$9.0(0.278)$} & 5 & 0.2978 & 0.3903 & 0.9855 & $-2.6 \mathrm{E}-15 \pm 0.1300$ \\
\hline & & 10 & 0.2988 & 0.3925 & 0.9902 & $-4.9 \mathrm{E}-16 \pm 0.1136$ \\
\hline & & 20 & 0.2978 & 0.3895 & 0.9879 & $-2.2 \mathrm{E}-16 \pm 0.1322$ \\
\hline
\end{tabular}




\begin{tabular}{|c|c|c|c|c|c|c|}
\hline & & 5 & 0.2567 & 0.4776 & 0.9913 & $-2.0 \mathrm{E}-15 \pm 0.1056$ \\
\hline & $4.15(0.223)$ & 10 & 0.2605 & 0.3904 & 0.9942 & $-1.4 \mathrm{E}-15 \pm 0.0902$ \\
\hline & & 20 & 0.2566 & 0.4784 & 0.9941 & $2.2 \mathrm{E}-16 \pm 0.0971$ \\
\hline & & 5 & 0.2849 & 0.4776 & 0.9913 & $5.4 \mathrm{E}-16 \pm 0.0957$ \\
\hline \multirow[t]{5}{*}{ TR-525 } & $4.7(0.252)$ & 10 & 0.2844 & 0.5676 & 0.9937 & $-5.6 \mathrm{E}-15 \pm 0.0835$ \\
\hline & & 20 & 0.2844 & 0.5674 & 0.9945 & $-1.4 \mathrm{E}-15 \pm 0.0801$ \\
\hline & & 5 & 0.3101 & 0.4315 & 0.9915 & $-1.1 \mathrm{E}-15 \pm 0.2253$ \\
\hline & $5.4(0.290)$ & 10 & 0.3100 & 0.4327 & 0.9954 & $-3.6 \mathrm{E}-15 \pm 0.1679$ \\
\hline & & 20 & 0.3099 & 0.4334 & 0.9963 & $-1.3 \mathrm{E}-16 \pm 0.1560$ \\
\hline
\end{tabular}

[*] $\mathrm{RE}=$ Mean residual error, $\mathrm{SD}=$ standard deviation of residual error.

For each TBR set at (or close to) nominal $\mathrm{V}_{\text {tip }}$, the calculated $\mathrm{V}_{\text {tip }}$ was always greater than the actual value (table 4). Similar to these observations, TBRs set at any $V_{\text {tip }}$ resulted in greater than actual volume per tip. In other words, at any given volumetric setting, TBRs tend to accumulate more than actual volume per tip, and hence underestimate the actual rainfall. The calculated tipping times $(\mathrm{t})$ ranged from 0.214 to $0.263 \mathrm{sec}$ in case of HS-TB3, 0.283 to 0.476 sec in case of ISCO-674, and 0.39 to $0.568 \mathrm{sec}$ in case of TR-525. The average measured values of t were $0.36,0.32$, and $0.38 \mathrm{sec}$, for the three TBR models, respectively.

\subsubsection{Quadratic model for intensity and depth correction:}

Applying the quadratic model suggested by Costello and Williams (1991) with multiple linear regression analysis resulted in three derived coefficients $\left(b_{0}, b_{1}\right.$, and $\left.b_{2}\right)$ and the corresponding $\mathrm{R}^{2}$ values for each TBR and volumetric setting combination (table 5). Regression models based on 20-min intervals resulted in better fits compared to those based on other time intervals $\left(1,2,5\right.$ and 10 minutes, not reported). Data from models ISCO-674 $\left(\mathrm{R}^{2}=0.85\right.$ to 0.92$)$ and TR-525 $\left(\mathrm{R}^{2}=0.75\right.$ to 0.91$)$ showed a better fit compared to those from HS-TB3 $\left(\left(\mathrm{R}^{2}=0.68\right.\right.$ to 0.72$)$. All regression models resulted in negative values of mean residual errors (of the order of $10^{-17} \mathrm{~mm}$ ) with relatively high standard deviations (of the order of $10^{-3} \mathrm{~mm}$ ). The quadratic models fitted to TR-525 data showed greater standard deviations in residual errors compared to models HS-TB3, and ISCO-674.

Table 5 Coefficients for quadratic model - $V_{\text {tip }}(i)$ as a function of measured intensity (20-minute)

\begin{tabular}{|c|c|c|c|c|c|c|}
\hline \multirow[t]{2}{*}{ TBR model } & \multirow{2}{*}{$\begin{array}{c}\text { Actual } V_{\text {tip }} \\
\text { ml tip }^{-1}\end{array}$} & \multirow{2}{*}{$\begin{array}{c}\mathbf{b}_{0} \\
\text { constant }\end{array}$} & \multirow{2}{*}{$\begin{array}{c}b_{1} \\
\text { 1st order }\end{array}$} & \multirow{2}{*}{$\frac{b_{2}}{2 n d \text { order }}$} & \multirow{2}{*}{$\mathbf{R}^{2}$} & \multirow[b]{2}{*}{$* \mathbf{R E} \pm \mathbf{S D}$} \\
\hline & & & & & & \\
\hline \multirow{3}{*}{ HS-TB3 } & 6 & 0.2321 & $-2.65 \mathrm{E}-4$ & 7.92E-7 & 0.72 & $-3.7 \mathrm{E}-17 \pm 3.97 \mathrm{E}-3$ \\
\hline & 7.5 & 0.2335 & $3.00 \mathrm{E}-4$ & $-9.58 \mathrm{E}-7$ & 0.68 & $-2.0 \mathrm{E}-16 \pm 4.16 \mathrm{E}-3$ \\
\hline & 8.3 & 0.2671 & $5.86 \mathrm{E}-4$ & $-2.50 \mathrm{E}-6$ & 0.72 & $-9.9 \mathrm{E}-17 \pm 5.09 \mathrm{E}-3$ \\
\hline \multirow{3}{*}{ ISCO-674 } & 7 & 0.2064 & $3.97 \mathrm{E}-4$ & $-1.06 \mathrm{E}-6$ & 0.85 & $-5.3 \mathrm{E}-17 \pm 4.42 \mathrm{E}-3$ \\
\hline & 8.1 & 0.2527 & $1.09 \mathrm{E}-4$ & $2.91 \mathrm{E}-7$ & 0.87 & $-1.1 \mathrm{E}-16 \pm 3.23 \mathrm{E}-3$ \\
\hline & 9 & 0.2952 & $1.11 \mathrm{E}-4$ & 4.47E-7 & 0.92 & $-9.0 \mathrm{E}-17 \pm 2.87 \mathrm{E}-3$ \\
\hline
\end{tabular}




\begin{tabular}{lcccccc}
\hline \multirow{2}{*}{ TR-525 } & 4.15 & 0.2219 & $4.12 \mathrm{E}-4$ & $-4.41 \mathrm{E}-7$ & 0.91 & $-2.1 \mathrm{E}-17 \pm 5.95 \mathrm{E}-3$ \\
& 4.7 & 0.2627 & $4.39 \mathrm{E}-4$ & $-6.73 \mathrm{E}-7$ & 0.86 & $-2.0 \mathrm{E}-16 \pm 6.69 \mathrm{E}-3$ \\
& 5.4 & 0.2822 & $6.44 \mathrm{E}-4$ & $-2.04 \mathrm{E}-6$ & 0.75 & $-7.8 \mathrm{E}-17 \pm 6.62 \mathrm{E}-3$ \\
\hline
\end{tabular}

[*] $\mathrm{RE}=$ Mean residual error, $\mathrm{SD}=$ standard deviation of residual error.

\subsubsection{Optimal volumetric calibration for minimal measurement errors}

The values of $t$ estimated using the $\mathrm{T}$ vs. 1/Q model could not be verified experimentally due to instrumental limitations. Therefore, methods suggested by Marsalek (1981) could not be used. Instead, a more simplified approach was used to find out the optimum volumetric setting for each TBR. Theoretically, the measurement error would be zero when the slope of regression line between measured versus actual intensities is equal to one. Therefore, coefficients (slope, m) derived from intensity curves (table 3) were plotted against the corresponding volumetric settings, and the resulting curves (fig. 3) were used to determine the volume per tip that would correspond to a slope value $(\mathrm{m})$ of 1 for the respective TBR models. The TBR models can then be set at these volume per tip settings, as suggested by Marsalek (1981). This approach eliminates the requirement of using any calibration equations for correcting field-measured rainfall data. The optimum volumes were determined to be 7.3 $\mathrm{ml} \mathrm{tip}^{-1}$ for HS-TB3, $7.4 \mathrm{ml} \mathrm{tip}^{-1}$ for ISCO-674 and $3.5 \mathrm{ml} \mathrm{tip}^{-1}$ for TR-525 (fig. 3). At these volumes, the slope of the intensity curves would be equal to one, suggesting theoretically zero measurement errors.

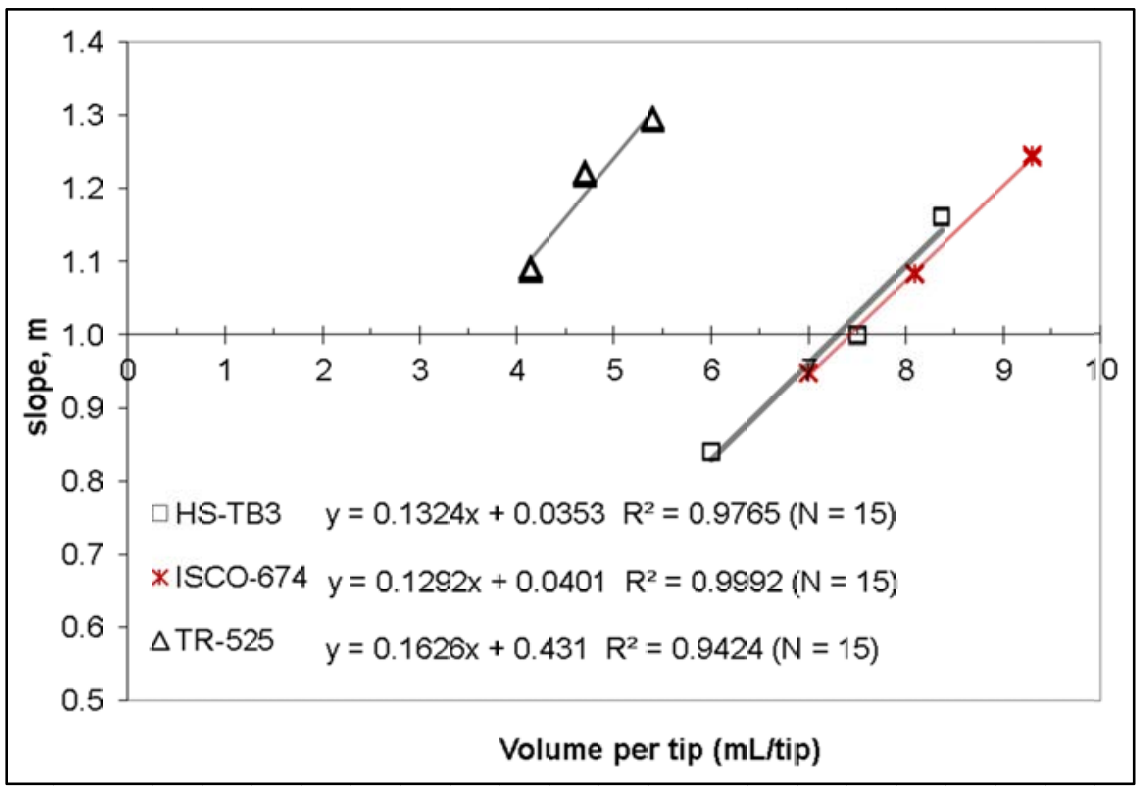

Fig. 3 Effect of bucket volume and volumetric setting on calibration parameters (Slopes, $m$ ) of intensity curves for the three TBR models. 
Another approach could be to use the percent error curves (fig. 2) and select the volumetric setting associated with the least or zero error. In cases of models ISCO-674 and TR-525, the measurement errors tend to be more negative with increasing rainfall intensities, suggesting that the measurement errors in these two models are intensity-dependent. Thus, it is practically impossible to attain 100\% accuracy in measurements of ISCO-674 and TR-525 simply by setting them at an optimum volumetric setting. The measurement errors of model HS-TB3, however, tend to remain uniform over all flow rates for each volumetric setting. This suggests that HS-TB3 could be set at an optimum volumetric setting that would lead to (theoretically) zero measurement errors. Since, volumetric calibration of TBRs changes over time due to environmental factors it may be challenging to maintain the optimum volumetric settings obtained above for an extended period of time.

\subsection{FIELD EXPERIMENT AND VALIDATION OF STATISTICAL MODELS FOR CORRECTION OF FIELD DATA}

\subsubsection{Field Comparison of TBRs}

Sample data were collected at the WANRL for 8 different storm events during 2011 and 2012 (fig. 4). In general, all the TBRs underestimate rainfall depths for all the storm events, compared to those measured by adjacent SNRG.

The overall underestimation error was greatest in the case of ISCO-674 (average deviation $=-25.9 \%$ ), followed by TR-525 (average deviation $=-17.3 \%$ ) and HS-TB3 (average deviation $=-1.9 \%$ ), respectively.

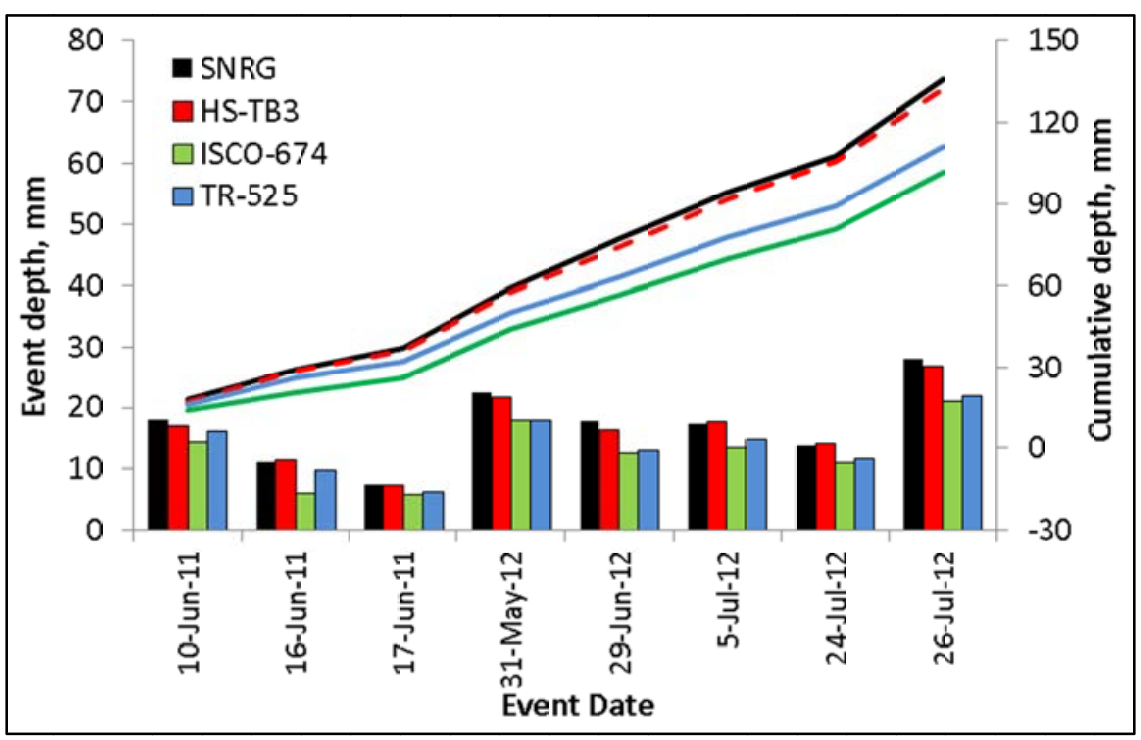

Fig. 4 Rainfall data measured by three TBRs at the WANRL during 8 storm events compared to data recorded at the adjacent SNRG (Bars represent event totals, and lines represent cumulative rainfall depth).

Since errors in HS-TB3 measurements were too small to apply corrections, only data from ISCO-674 and TR-525 were used and compared with those from the SNRG and HS-TB3. Furthermore, rainfall data from the USDA-ARS 
Riesel Watershed (site RG-70) were used to test the performance of statistical correction models for HS-TB3, as follows.

\subsubsection{Corrections to HS-TB3 measurements}

The data collected by HS-TB3 at the WANRL matched closely (average deviation $=-1.9 \%$ ) with the SNRG measurements (fig. 4). Therefore no correction was required for the HS-TB3 model. It was observed that the volumetric setting of HS-TB3 was not set at the nominal volume. The volume per tip as measured in the field was $7.5 \mathrm{ml}$ tip-1. This further verifies the results obtained from the lab experiment, and establishes that model HS-TB3 is more accurate when set at a volume less than the nominal volume.

The three statistical models developed for the model HS-TB3 were applied to data collected at site RG-70 in the USDA-ARS Riesel Watershed (fig. 5). The average percent deviation of daily depths measured by HS-TB3 from those measured by the adjacent SNRG was $-15 \%$. After applying corrections, the average percent deviation changed to $-1.4 \%$ with the slope method, $-7.5 \%$ with the quadratic model, and $-3.6 \%$ with the $\mathrm{T}$ vs. $1 / \mathrm{Q}$ model. Thus, the intensity curve-based approach seemed to reasonably correct the measured rainfall data, followed by the T vs. 1/Q model and the quadratic model, respectively.

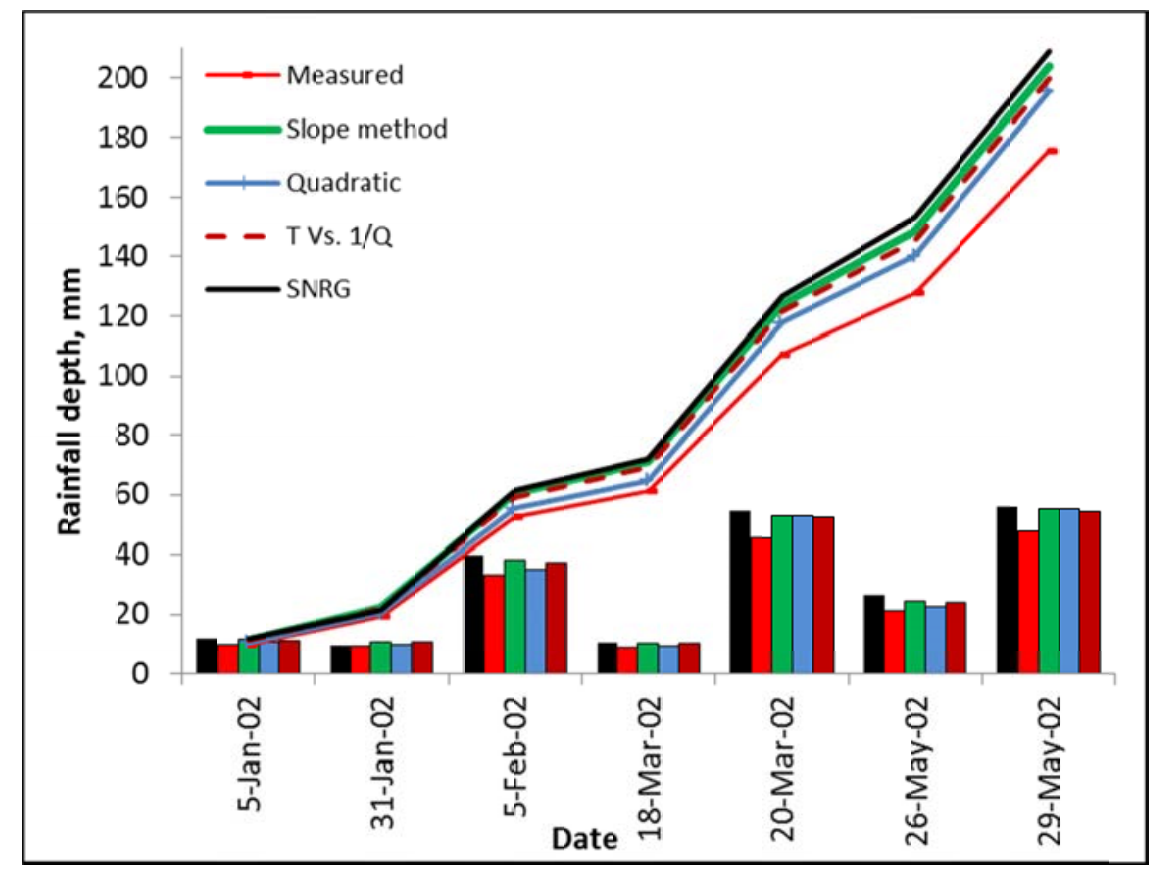

Fig. 5 Corrections applied to 10-minute rainfall data measured by HS-TB3 at RG70 site in USDA-ARS Riesel Watershed (Texas).

(Bars show daily rainfall depths, and lines show cumulative rainfall. The 7 days were selected from the period of January 2002 through May 2002, such that a range of rainfall intensities were reflected) 


\subsubsection{Corrections to ISCO-674 measurements}

The three statistical models were applied to correct ISCO-674 measurements during a storm event on June 10, 2011 at the WANRL (fig. 6). The storm depth recorded by SNRG was $18.03 \mathrm{~mm}$; and that recorded by ISCO-674 was $14.22 \mathrm{~mm}$ (underestimation of about $21 \%$ ). The corrections based on the slope method seemed to perform better (corrected depth of $16.07 \mathrm{~mm}$ ), followed by the T vs. 1/Q method (corrected depth of $15.41 \mathrm{~mm}$ ) and then the quadratic model (corrected depth of $15.17 \mathrm{~mm}$ ). The slope method reduced the underestimation error from $21 \%$ to about $10.8 \%$, followed by the T vs. 1/Q model (14.6\%) and the quadratic model (15.9\%). Thus, corrections applied to ISCO-674 using any of the three methods proved to be inadequate. Although the TBRs were being monitored on a weekly basis, it was observed that the ISCO-674 model was particularly susceptible to frequent clogging as observed, possibly due to the small aperture size of the funnel. Due to partial clogging a lesser number of tips may have been recorded with ISCO-674, resulting in excessive underestimation of rainfall depth. The clogging issues combined with frequent technical issues with data loggers attached to ISCO-674 limited the data availability for additional comparison ${ }^{1}$.

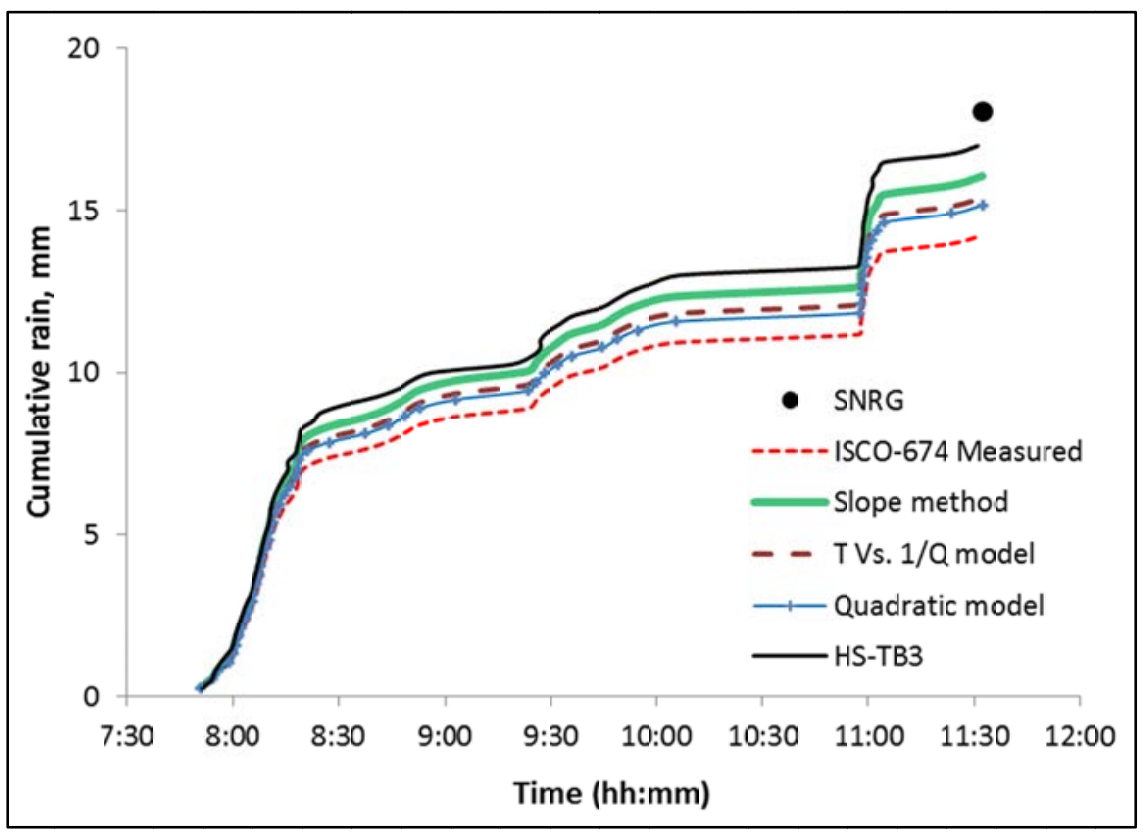

Fig. 6 Cumulative rainfall measured by model ISCO-674 and corrected using dynamic calibration techniques for a storm on 10 June, 2011 recorded at the WANRL

(Dot indicates total depth of rainfall recorded by SNRG, i.e. $18.03 \mathrm{~mm}$. HS-TB3 data are included for relative comparison at each time step)

${ }^{1}$ The three statistical models for the model ISCO-674 were successfully validated using data from another monitoring site in the Upper Big Walnut Creek Watershed, Ohio USA (data not reported here).

21 


\subsubsection{Corrections to TR-525 measurements}

Although it was calibrated frequently for the nominal bucket volume $(4.7 \mathrm{ml})$ per tip, TR-525 was particularly susceptible to change in volumetric setting over time. Corrections were applied to the TR-525 measurements of storm event on June 10, 2011 at the WANRL using all three dynamic calibration techniques, i.e., coefficient of intensity curves, $\mathrm{T}$ vs. 1/Q model and quadratic model (fig. 7). The storm depth recorded by TR-525 was $16 \mathrm{~mm}$, compared to $18.03 \mathrm{~mm}$ recorded by SNRG and $17 \mathrm{~mm}$ recorded by HS-TB3. Thus, TR-525 underestimated the rainfall by about $11.3 \%$ compared to that recorded by SNRG. The T vs. 1/Q method-based corrections resulted in closest estimate $(18.1 \mathrm{~mm}$ ) of actual rainfall (deviation changed from $-11.3 \%$ to $+0.5 \%)$. The two other techniques showed similar performance with intensity curve based slope method $(17.6 \mathrm{~mm}$, deviation of $-2.4 \%$ from actual depth) slightly better than the quadratic model $(17 \mathrm{~mm}$, deviation of $-5.8 \%$ from actual depth). Thus, all three techniques were able to successfully correct the TR-525 measurements, provided that the volumetric setting of the TBR was known.

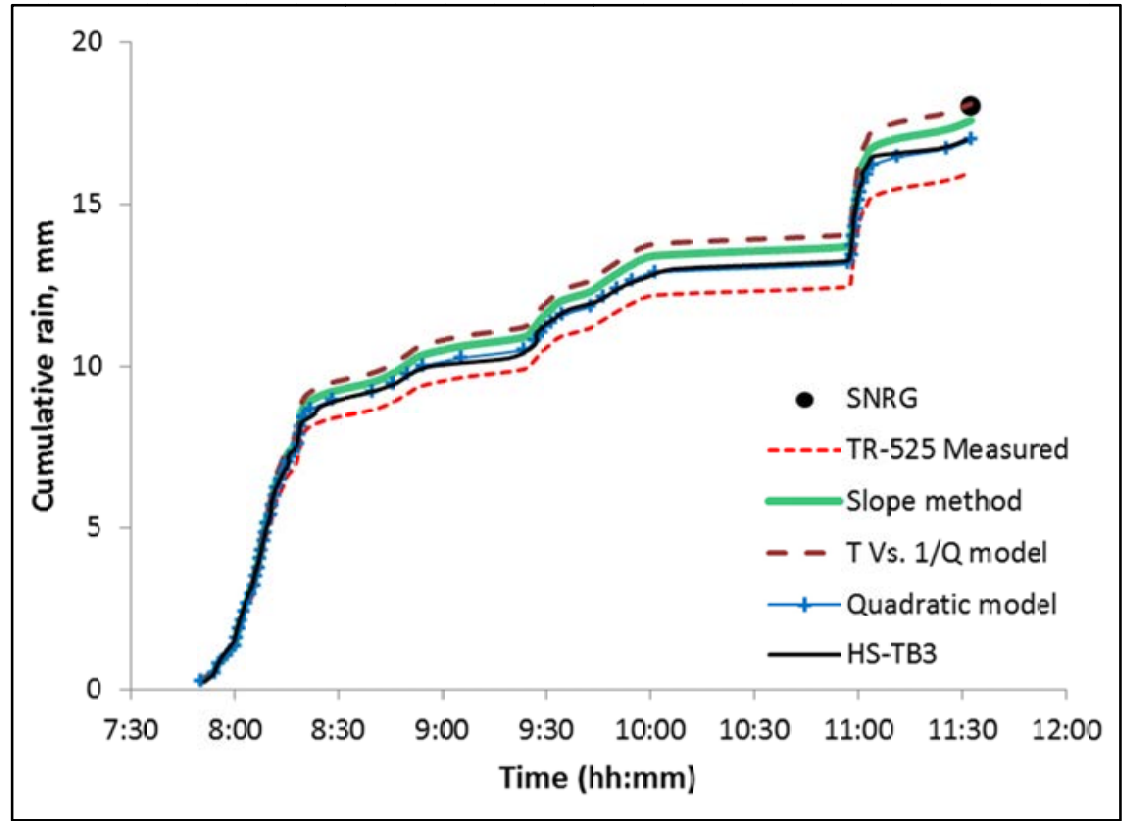

Fig. 7 Cumulative rainfall measured by model TR-525 and corrected using dynamic calibration techniques for a storm on 10 June, 2011 recorded at the WANRL

(Dot indicates total depth of rainfall recorded by SNRG, i.e. $18.03 \mathrm{~mm}$. HS-TB3 data are included for relative comparison at each time step)

The intensity curve based method was further used to correct TR-525 measurements of about 30 storm events at WANRL during 2011 and 2012 (fig. 8). Although some storm depths were under- or overestimated in some cases, 
overall the corrected data matched closely (average percent deviation changed from $-11.7 \%$ to $-0.3 \%$ after corrections) with the rainfall depths observed at SNRG.

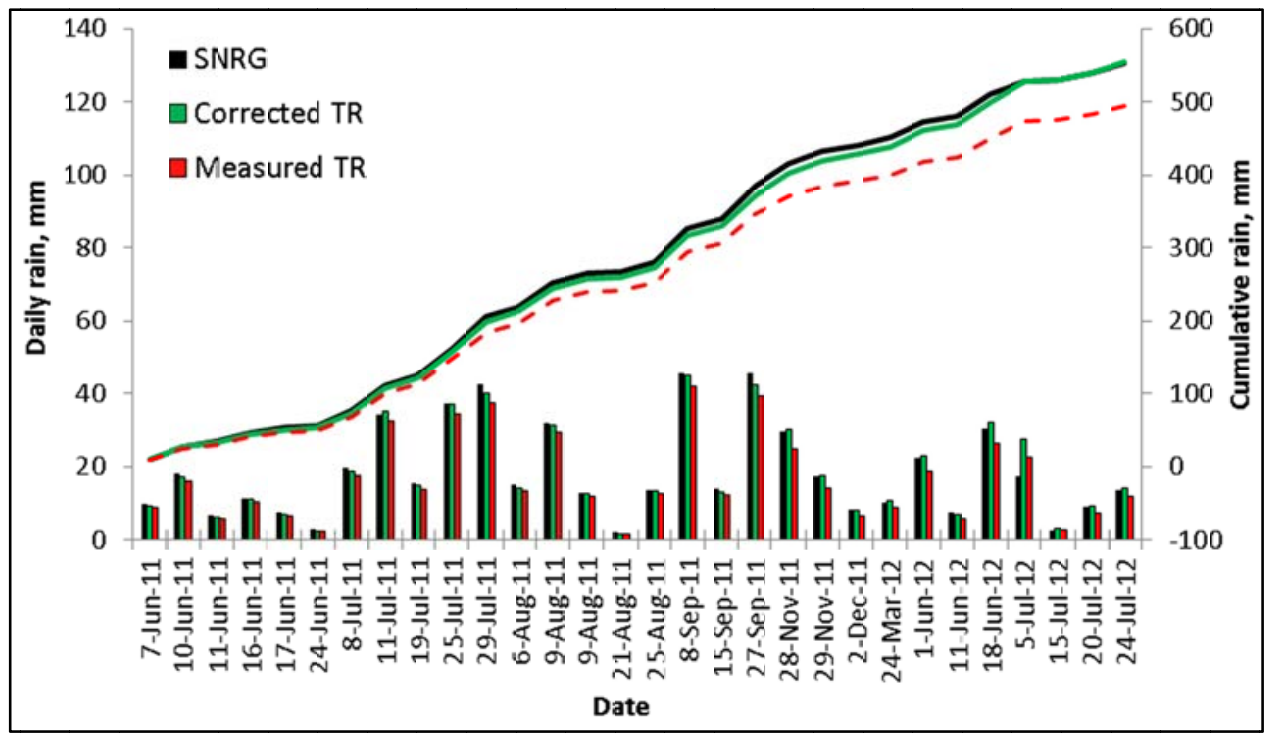

Fig. 8 Intensity curve-based (slope method) corrections applied to "time-of-tip" based rainfall data recorded by TR-525 at the Waterman farm (Bars represent storm event totals, and lines represent cumulative rainfall)

\subsection{A NOTE ON PARTIAL CLOGGING OF TBRS}

During the field experiments, a few important observations were made that relate to proper installation and maintenance of TBRs. All three TBRs are susceptible to clogging, primarily by bird droppings. Fig. 9 shows an example storm measured by the three TBRs during May 31, 2012 through June 1, 2012. In fig. 9, HS-TB3 readings are considered to be "actual" since HS-TB3 data (total storm depth) were not significantly different from the corresponding SNRG readings $(\alpha=0.05)$. Fig. 9(a) compares HS-TB3 measurements with those of ISCO-674 and further compares the corrections applied to ISCO-674 data using the three methods. Similarly, fig. 9(b) compares the measured and corrected data from TR-525 with those from HS-TB3 during the same storm. 


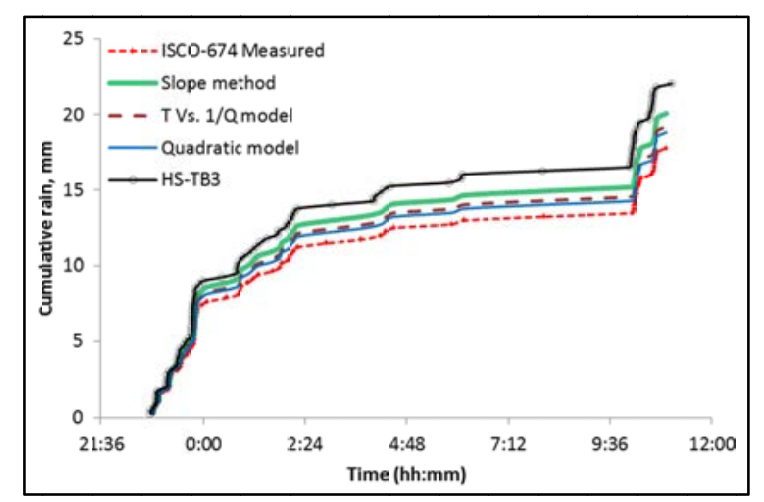

(a) ISCO-674 data for entire storm

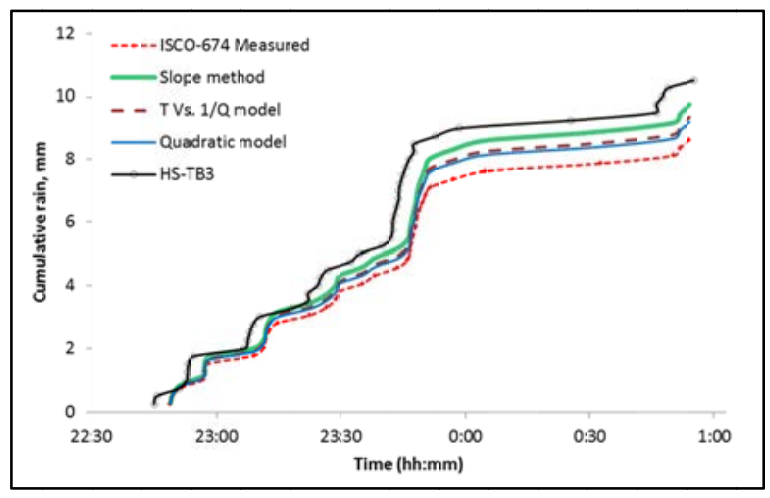

(c) ISCO-674 data during hours 22:45 and 01:00

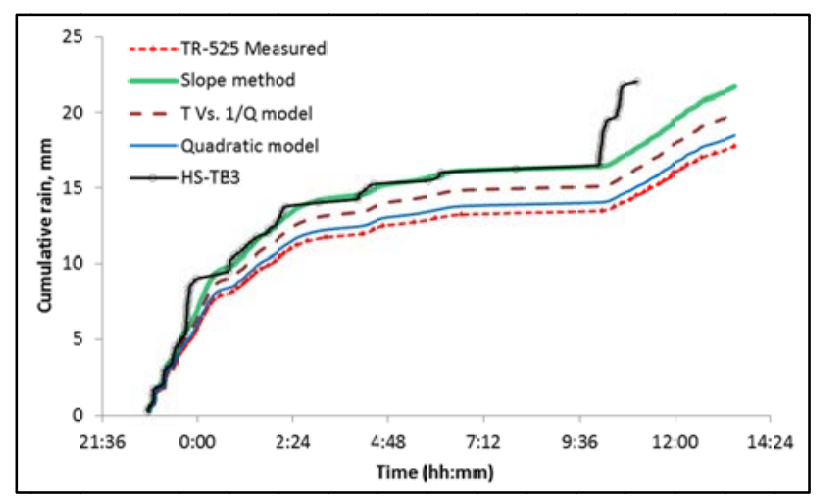

(b) TR-525 data for entire storm

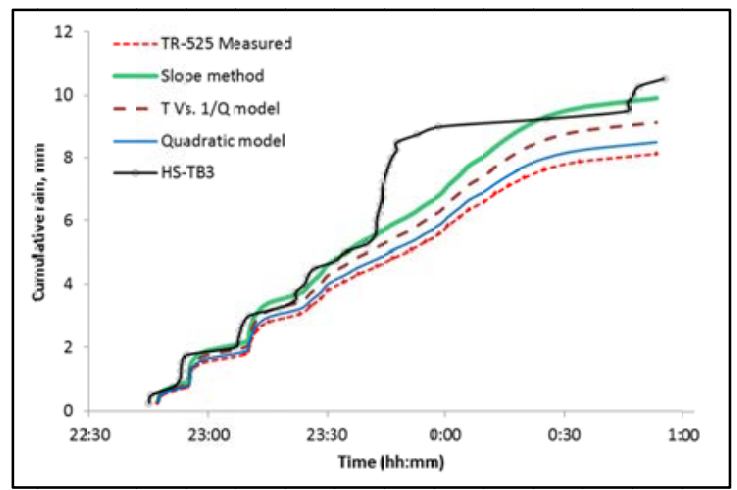

(d) TR-525 data during hours 22:45 and 01:00

Fig. 9 Cumulative rainfall measured by TBRs for a storm on 31 May through 1 June, 2012 and corrected using the three dynamic calibration techniques

(The measurements of HS-TB3 are assumed to be actual rainfall measurements)

Unlike ISCO-674, the measured and corrected data series of TR-525 didn't follow the same trend as that of HSTB3, especially between the hours of 22:45-1:00 and 10:00-14:24. The hours of 22:45 through 01:00 are further enlarged fig.s 9(c) and 9(d) to give a closer look at the observed and corrected measurements of ISCO-674 and TR525, respectively. The measurements of ISCO-674 and HS-TB3 follow similar trends (fig. 9(a) and fig. 9(c)). However, model TR-525 data suggests a seemingly constant rate of rainfall between hours of 22:45 through 01:00 (fig. 9(d)), and 10:00 through 14:24 (fig. 9(b)). This is a clear indication of partial clogging of the funnel orifice of model TR-525. The excess rainfall water accumulated in the funnel, and then dripped down through the partially clogged orifice to the buckets at a constant rate, resulting in erroneous estimates of intensity and duration of the storm. 


\section{DisCuSSION OF RESULTS}

\subsection{MEASUREMENT ERRORS OF TBRS SET AT DIFFERENT VOLUMETRIC CALIBRATIONS}

Dynamic calibration showed that, when set at their nominal volumetric setting, all three TBR models underestimated rainfall intensities, and hence, cumulative rainfall at almost all flow rates (fig. 2). In general the variation in measurement errors was greater at low flow rates, and decreased from smaller to greater flow rates. Similar observations were made by Colli et al. (2014) while comparing measurements of a weighing rain gauge (WG) with those of a MTX TBR (MTX Srl, Campogalliano, Italy) in a laboratory. They reported average relative error of $1.6 \%$ with a standard deviation of $17.2 \%$ in rainfall intensities measured by the TBR at 1-minute intervals. Models TR-525 and ISCO-674 showed increasing underestimation errors at greater intensities, while model HS-TB3 showed relatively uniform errors across all flow rates. The relatively smaller percent error in ISCO-674 measurements may have resulted from the volumetric setting $\left(8.1 \mathrm{ml} \mathrm{tip}^{-1}\right)$ being slightly smaller than the nominal

volume $\left(8.24 \mathrm{ml} \mathrm{tip}^{-1}\right)$. Various studies indicated that the underestimation errors in TBRs may range from $10 \%$ to $30 \%$ for rainfall intensities greater than $25 \mathrm{~mm} \mathrm{~h}^{-1}$ and increase nonlinearly with increases in rainfall intensity (Marsalek 1981; Alena et al., 1990; Humphrey et al., 1997). The errors in measurements of three TBRs in this study were well within the reported range.

\subsection{FACTORS AFFECTING DYNAMIC CALIBRATION AND ERRORS IN TBR MEASUREMENTS}

Rainfall intensity, bucket volume, volumetric calibration, and time interval were identified as the main factors affecting errors in TBR measurements during dynamic calibration.

\subsubsection{Effect of rainfall intensity on dynamic calibration:}

The general trends of average measurement errors suggest that the errors in TBR measurements are dependent on rainfall intensities for the models ISCO-674 and TR-525. However, the measurement errors of HS-TB3 seem to remain consistent regardless of the rainfall intensity (fig. 2). Model HS-TB3, unlike the other two models, has a siphon mechanism at the bottom of its funnel. The siphon mechanism is set to siphon at each $0.254 \mathrm{~mm}$ increment, and may be the reason for the constant error over a range of flow rates. In the absence of a siphon mechanism, the tendency of TBRs to underestimate the rainfall at greater intensities may be attributed to greater loss of water during the tipping movement of the buckets. There is some time lapse between the start of movement to one side of the bucket and the instance when the second side comes under the funnel. During this time, some water is lost as it falls into the first bucket during its tipping movement. If it is assumed that the tipping time of the bucket remains 
constant, then greater amounts of water will be lost at greater rainfall rates and hence result in greater underestimation errors (Edwards et al., 1974). At flow rates greater than $2.5 \mathrm{~cm} \mathrm{~h}^{-1}$, all three TBRs resulted in increasing underestimation with rainfall intensities. The tendency of TBRs to underestimate higher rainfall intensities has been widely reported (Marsalek 1981; Alena et al., 1990; Sevruk, 1996; Humphrey et al., 1997). Conversely, Vasvàri (2005) reported that TBRs set at nominal volumetric settings tend to overestimate rainfall intensities lower than $6 \mathrm{~cm} \mathrm{~h}^{-1}$; and underestimate the intensities over $6 \mathrm{~cm} \mathrm{~h}^{-1}$ with underestimation errors proportional to rainfall intensities. Some observations at lower flow rates $\left(<2.5 \mathrm{~cm} \mathrm{~h}^{-1}\right)$ showed similar tendencies to overestimate (reflected by positive errors in fig 2) the rainfall intensities for all three TBRs under study. Furthermore, the calibration equations developed for intensity corrections are very sensitive to changes in the volumetric settings of TBRs. Therefore, calibration equations based on a single volume per tip setting may not be useful to correct all field-collected data. In this case, conducting frequent volumetric calibrations of TBRs in the field is recommended. If field-installed TBRs show a different volume per tip than the theoretical value, a calibration parameter $(\mathrm{m})$ for that volumetric setting can be derived (fig. 3). These parameters can then be used as constants in calibration equations in order to correct the field-collected data.

\subsubsection{Effect of bucket size on dynamic calibration:}

Bucket size (volume) is an important factor affecting the underestimation errors in the TBRs. If the water loss during tipping movement (i.e., during lapse time) is a small fraction of total bucket volume, then the corresponding relative error will be less. Model TR-525 has a bucket volume of $4.73 \mathrm{ml}$; while, ISCO-674 and HS-TB3 have a bucket volume of $8.24 \mathrm{ml}$. If the tipping time of buckets is similar in all models, then at any given intensity the amount of water lost during the tipping time (lapse time) will be almost the same. However, due to the smaller bucket size of TR-525, the percent water loss during tipping movement would be greater than the other two models. The greater the rainfall intensity, the greater would be the percent water loss. Thus, a smaller bucket size may result in relatively greater errors at greater rainfall intensities. Furthermore, any water left in` the bucket after tipping constitutes a variable counterweight and also reduces the mass required to tip when the nominally empty bucket returns for filling (Edwards et al., 1974). Barring (1992) suggested that during intense rainfall, TBRs tend to cause excessive integration (collect more than nominal volume per tip) which in turn results in isolated tips; and that this problem is amplified with a large tipping bucket size. WMO (1981) recommends that bucket sizes exceeding 0.2 mm should not be used for detailed measurements. Although, the different bucket volumes of all TBR models in the 
current study represent same rainfall depth $(0.254 \mathrm{~mm})$, model TR-525, which has a relatively smaller bucket volume $\left(4.7 \mathrm{ml} \mathrm{tip}^{-1}\right)$ compared to the two other TBRs, showed greater errors of measurement (fig. 2). Thus, a smaller bucket size, regardless of its rainfall depth representation may be associated with greater errors. Vasvàri (2005) observed similar behavior of TBRs and concluded that TBRs with smaller bucket sizes resulted in greater relative errors compared to TBRs with larger buckets (at intensities greater than $6 \mathrm{~cm} \mathrm{~h}^{-1}$ ).

\subsubsection{Effect of volumetric calibration on dynamic calibration}

The regression lines fitted for the slopes of calibration equations showed good agreement $\left(\mathrm{R}^{2}>0.94\right)$ with bucket volume (fig. 3). HS-TB3 measurements were most accurate at the volumetric calibration of $7.5 \mathrm{ml} \mathrm{tip}^{-1}$ (fig. 2, table 2). When the volumetric calibration was changed to $6 \mathrm{ml} \mathrm{tip}^{-1}$, the TBR overestimated the actual flow rates. Although, changing the tipping volume from $8.3 \mathrm{ml} \mathrm{tip}^{-1}$ to $7.5 \mathrm{ml} \mathrm{tip}^{-1}$ caused about $9 \%$ overestimation error in the volumetric calibration of model HS-TB3, it compensated for about $83 \%$ of (12 out of 14\%) underestimation errors at nominal volume. For the ISCO-674 model, the volumetric calibration of $8.1 \mathrm{ml} \mathrm{tip}^{-1}$ seemed to be the optimal volume required for the greatest accuracy of measurements (fig. 2, table 2). The errors in flow rate measurements at the nominal volume ranged from $-22.5 \%$ to $+31 \%$, with the median error of about $-6 \%$. The measurements of ISCO674 showed sensitivity to volumetric calibration as well as flow rate. The measurement errors became more negative at greater flow rates. At volume settings above the nominal volume (i.e., $7 \mathrm{ml}$ tip ${ }^{-1}$ ), model ISCO-674 overestimated the actual flow rates, with measurement errors ranging from $+0.9 \%$ to $+18.7 \%$. When the volumetric calibration was set above nominal volume $\left(9 \mathrm{ml} \mathrm{tip}^{-1}\right)$, model ISCO-674 underestimated the actual flow rates, with measurement errors ranging from $-23.7 \%$ to $-5.9 \%$ (table 2). Model TR-525 showed results similar to those for ISCO-674. At a nominal volume $\left(4.7 \mathrm{ml} \mathrm{tip}^{-1}\right)$, the model TR-525 underestimated the flow rates with measurement errors ranging from $-53.7 \%$ to $+39 \%$ (table 2 ). When it was set at volumetric setting below the nominal volume $\left(4.15 \mathrm{ml} \mathrm{tip}^{-1}\right)$, TR525 overestimated the lower range and underestimated the higher range of flow rates (fig. 2). The measurement errors at this setting ranged from $-14.5 \%$ to $+16.5 \%$ with an average error of $-1.9 \%$. The errors ranged from $-27 \%$ to $-13 \%$ when this TBR was set at volume greater than the nominal volume $\left(5.4 \mathrm{ml} \mathrm{tip}^{-1}\right)$ with an average error of $20.9 \%$, suggesting greater underestimation by the TBR. The results presented above illustrate the sensitivity of TBRs to volumetric calibration and the fact that the optimum volumetric calibration can be different than its theoretical value in order to achieve greater accuracy. When set at a lower than nominal volumetric setting, the bucket compartments take less than the nominal tipping volume and, consequently, overestimating the actual rainfall 
intensity such that it compensates for the underestimation errors. This approach seems to be the most practical approach; as it eliminates the requirement of post-processing the field collected data using any calibration equations.

\subsubsection{Effect of recording time interval on dynamic calibration:}

Selecting appropriate time interval for recording rainfall usually depends on the power requirement and available memory of the data logger. The shorter the time interval, the better the possibility of capturing true rainfall intensities. Most hydrologic applications assume an uniform rainfall intensity over the entire time interval. The data correction methods that are based on rainfall intensity would fail if the true rainfall intensities were not captured. Habib et al. (2001), in a lab study, suggested that the TBR estimates incur significant errors if based on time intervals less than 10 to $15 \mathrm{~min}$. They observed significant errors in the 1-min estimates especially at less rainfall intensities. The TBR's performance and associated errors were found to be sensitive to the time interval and nominal bucket volume. Habib et al. further recommended using fine resolution of both, the sampling time and the bucket size in order to minimize uncertainty in estimates of rainfall intensities. Although, a 1 min interval was used in the current study, these data were summarized over 1, 2, 5, 10 and $20 \mathrm{~min}$, respectively, in order to study the effect of time interval. Time interval did not affect the calibration parameters calculated for intensity curves (table 3 ). However, the time intervals of 1 and 2 min resulted in unrealistic calibration parameters for the $T$ vs. 1/Q model compared to longer intervals of 5, 10 and 20 min (table 4). Similarly, the quadratic models performed better at longer time intervals. Thus, it is important to run lab experiments for long enough time periods, such that reliable calibration parameters can be derived using different time intervals for data aggregation.

Ciach (2003) observed that the method of simple tip counting constitutes much larger errors as compared to the time-of-tip method. In another similar experiment, Costello and Williams (1991) found that intensities measured using the time-of-tip method were significantly greater than conventional recording methods; with greater differences observed when the recording interval exceeded the storm duration. At lower intensities when the time between tips is longer than the set time interval, the rainfall depth is recorded over the length of two time intervals. However, if the calculations are set to calculate depth and/or intensity and calculated for each individual time interval, they are likely to be underestimated for the previous time step, and overestimated for the following time step. Thus, in case of low rainfall intensities, it is advisable to use relatively longer time intervals or the 'time of tip' recording method. On the other hand, greater rainfall intensities generally last only for a short duration. Thus, if time interval is longer than the duration of high rainfall intensities, the TBR is likely to underestimate the intensities 
during those time intervals. Therefore, in the case of greater rainfall intensities, a shorter time interval is recommended. The 'time of tip' recording method may help achieve both goals. This approach helps calculate rainfall intensities for every incremental rainfall depth (equal to depth resolution of model). The only drawback of this method is the fact that the starting time of each storm remains unknown. This becomes important specifically during low intensity storms. The time is not recorded until the first bucket tip occurs due to rainfall. However, the intensity for the first recorded bucket cannot be estimated. In such a situation, it can be assumed that the intensity for the first recorded tip of the TBR was the same as that for the subsequently recorded tip.

Sieck et al. (2007) compared measurements of observed rainfall by 34 different rain gauges representing 6 different models in the Goodwin Creek watershed in northern Mississippi. Three out of the 6 models were TBRs including the HS-TB3. They suggested that along with volumetric calibration, wind effects and raindrop size contribute significantly to the under-catch of rain gauges in general. Similar inference can be drawn from the results of the current study. In general, although the corrected rainfall series from all three TBRs were close to those from the SNRG, the two data series didn't match precisely. This implies that even if the calibration equations help minimize the errors in rainfall estimation; there will always be some errors due to other external factors. In other words, corrections based on dynamic and volumetric calibration can only help minimize- and not completely eliminate the measurement errors. Similar conclusions were reported by Edwards et al. (1974) and Niemezynowiez (1986). Overall, model HS-TB3 seems to be the most reliable and consistent model for rainfall measurements, followed by ISCO-674 and TR-525.

\subsection{ISSUES RELATED TO INSTALLATION AND MAINTENANCE OF TBRS}

All three TBRs were found to be susceptible to clogging, primarily by bird droppings. Although, the mesh cover provides some level of protection, it is also likely to attract more birds. An example in fig. 9 shows that it may be possible to identify partial or complete clogging based on the general trend of records. Although, some efforts have been taken to detect such issues in real-time data (Upton and Rahimi, 2003), it may be difficult to identify all such errors without any validation of the issue in the field. Ciach (2003) suggested that measurement networks that have two or more rain gauges on each station, significantly improve early detection of instrument failures. Since, the tipping bucket mechanism of most TBR models is not completely sealed; it is susceptible to dirt accumulation, spider webs and insect nests. This may affect the volumetric calibration of TBRs, and hence result in inconsistent errors that are difficult to identify and correct. Model HS-TB3 seems to provide the most protection to the tipping 
bucket mechanism from external elements, as compared to ISCO-674 and TR-525. It is essential to monitor the TBRs as frequently as possible. TBRs installed on a poorly constructed platform, swaying action caused by winds may cause them to register additional tips, especially when the buckets are partially filled (Sieck et al., 2007). Thus, in order to ensure reliable measurements from TBRs, it is essential to develop a monitoring plan that involves careful installation, regular maintenance, and frequent lab and/or field testing.

\subsection{IMPLICATIONS TO HYDROLOGIC STUDIES}

The errors in estimates of rainfall depth and intensity may have significant impacts on other hydrologic applications such as: flood forecasting (Sun et al., 2000) and flash flood warning (Michaud, 1994); design and analysis of urban drainage systems (Rauch et al., 1998; Molini et al., 2005); rainfall-runoff model parameters (Lopes, 1996; Habib et al., 2008); storm sewer flows (Zhu and Schilling, 1996); and hydrologic modeling (Larson and Peck, 1974; Baffaut et al., 2015). Rain gauge data are also used as reference for calibration and quality control of spatially distributed techniques such as satellite and radar (Wood et al., 2000; Habib et al., 2001; Krajewski and Smith, 2002). The accuracy of TBRs that are part of such networks is critical for minimizing error propagations in the calibrated rainfall data sets. The uncertainty and errors associated with tipping bucket mechanism have also been reported for hydrologic applications involving continuous flow (from runoff, drainage) measurements in field and watershed scale experiments (Yu et al., 1997; Zhu et al., 2004).

Most watershed scale studies involve recording precipitation data using TBRs. The results from the current study indicate that volumetrically calibrated TBR models cause significant underestimation errors in measured precipitation data. The magnitude of errors in TBR measurements increases with increasing rainfall intensity. Consequently the magnitude of errors is larger in estimation of extreme events, which in turn guide the safety of the design of conservation structures and practices (e.g., estimating peak runoff, peak flood levels). If such data are being used for a hydrologic simulation modeling study, it is important to test the sensitivity of the respective simulation models to the underestimation errors of TBRs. Errors in precipitation measurements may cause significant biases in the outputs of simulation models that use precipitation data inputs at field- as well as watershedscales (Fankhauser, 1997; Andréassian et al., 2001; Chaplot et al., 2005). In their recent studies, La Barbera et al. (2002) quantified the general biases in the quantification of return periods and other statistics of rainfall extremes as affected by the systematic mechanical errors in TBR measurements. A similar study was carried out by Molini et al. (2005) to estimate the impact of TBR measurement errors on depth-duration-frequency curves and design rainfall 
for urban-scale applications in Italy. Some preliminary analysis of field-scale modeling results using DRAINMODNII by Shedekar et al. (2009) suggested that the drainage outflow and runoff were significantly affected after applying the corrections to field-measured rainfall data collected at 10-min intervals. Consideration of these errors may also be helpful for model calibration. Corrected precipitation input to the simulation model should ensure better calibration of the model. Current practices of estimating simulation model uncertainty assume no or small uncertainty in precipitation data measured by TBRs. However, the uncertainty associated with TBRs should be based on the understanding that TBRs always have an inherent uncertainty in addition to field measurement errors.

\section{CONCLUSIONS AND RECOMMENDATIONS}

The results of dynamic calibration indicate that all three TBR models showed substantial underestimation error in measurements, particularly at high rainfall intensities. Model TR-525 was found to be more sensitive to rainfall intensities with earlier and larger deviations from actual values, as compared to models ISCO-674 and HS-TB3. All three TBRs (set at their respective nominal volumes) underestimated the rainfall depths at rainfall intensities ranging from 6 to $235 \mathrm{~mm} \mathrm{hr}^{-1}$. Average errors in measurements of TBRs set at their respective nominal volumes were $14.2 \%$ for TR-525 and HS-TB3, and $-5.3 \%$ for ISCO-674. The underestimation errors were relatively uniform in case of HS-TB3 regardless of intensity. However, models TR-525 and ISCO-674 showed increasing underestimation errors at greater intensities. At higher than nominal volumetric calibration, the TBRs further underestimate the rainfall depths. Conversely, at lower than nominal volumetric calibration the TBRs tend to

overestimate the rainfall depths. The deviations in TBR measurements may be attributed to the small amount of water loss during each tipping movement. The rainfall intensity, bucket size, volumetric calibration, and time interval were identified as the main factors affecting the magnitude of errors in TBR measurements during dynamic calibration. TBRs with smaller bucket size may result in greater measurement errors at higher rainfall intensities. Conversely, TBRs with larger bucket size may cause isolated tips during intense rainfall events. The optimum volumetric calibration can be different than its theoretical value in order to achieve greater measurement accuracy. TBR measurements are very sensitive to volumetric calibration (volume per tip) which often changes due to natural factors in the field. Although, recording time interval doesn't seem to affect calibration parameters derived for intensity curves, it may become important at extremely high and low rainfall intensities. A shorter time interval is 
recommended for recording greater rainfall intensities, and vice a versa. The "time-of-tip" recording method may provide some advantages over the "fixed time interval" method.

Based on experimental data, simple linear regression models are proposed to correct measured rainfall intensities. With $R^{2}$ values above 0.98 , the simple linear regression models showed a good agreement between the actual and measured values of intensities for all three TBRs regardless of time interval. However, the correction factors (calibration parameters) were found to be highly sensitive to volumetric calibration of individual TBR models. The optimum volumetric calibrations (volumes per tip) were determined to be $7.3 \mathrm{ml} \mathrm{tip}^{-1}$ for HS-TB3, $7.4 \mathrm{ml} \mathrm{tip}^{-1}$ for ISCO-674 and $3.5 \mathrm{ml} \mathrm{tip}^{-1}$ for TR-525. At these volumes, the slope of the intensity curves would be equal to one, suggesting theoretically zero measurement errors. Two additional statistical models (viz. T vs. 1/Q model and quadratic model) were evaluated and proved to be useful in situations where the intensity curve-based approach could not be applied. A fourth approach was also suggested to set the volumetric settings of TBRs at optimal levels that would ensure minimal errors. However, this approach poses challenges, since volumetric calibration changes over time in most TBRs.

The side-by-side comparison of TBRs with a SNRG in the field suggested that the overall underestimation error was greatest in case of ISCO-674 (-26\%), followed by TR-525 (-17\%) and HS-TB3 (-2\%), respectively. All three TBRs are highly susceptible to clogging and require frequent maintenance. Since, the tipping bucket mechanism of most TBR models is not completely sealed; it is susceptible to dirt accumulation, spider webs and insect nests. It is recommended that the funnel, inner cylinder and the bucket mechanism be cleaned at least on weekly basis and definitely before the onset of major storms.

The calibration equations developed during the lab study were further evaluated for their performance using data collected from a field study at the WANRL and USDA-ARS Riesel Watershed, respectively. The intensity curvebased slope method proved to be the easiest and satisfactory for correcting field data. Field data from all TBRs were corrected with good accuracy using the slope method. However, the first and important step for minimizing errors associated with TBRs is adhering to installation guidelines regarding height, level, and location. Providing wind barriers around the gauge; and incorporating heaters for melting ice and snow may further help reduce errors due to external factors. The corrections based on dynamic and volumetric calibration can only help minimize- and not completely eliminate the measurement errors. Even if the calibration equations help minimize the errors in rainfall estimation; there will always be some errors due to other external factors. Overall, model HS-TB3 seems to be the 
most reliable and consistent model for rainfall measurements, followed by ISCO-674 and TR-525. Results of this study can be used to correct field data from the respective TBRs. Based on this study and published literature, errors in rainfall measurements may have major implications to hydrologic studies at field- and watershed scales. Future research should include the results from this study to test the implications to field and watershed-scale hydrologic modeling.

\subsection{RECOMMENDATIONS FOR FIELD INSTALLATION AND MAINTENANCE OF TBRS}

In general, TBRs are susceptible to frequent clogging, primarily by bird droppings. Since, the tipping bucket mechanism of most TBR models is not completely sealed; it is susceptible to dirt accumulation, spider webs and insect nests. This may affect the volumetric calibration of TBRs, and hence result in inconsistent errors that are difficult to identify and correct. Therefore, it is essential to monitor the TBRs as frequently as possible. It is recommended that the funnel, inner cylinder and the bucket mechanism be cleaned at least on a weekly basis and definitely before the onset of major storms. TBRs installed on a poorly constructed platform, swaying action caused by winds may cause them to register additional tips, especially when the buckets are partially filled. Thus, a careful installation is important at sites dominated by wind and presence of birds. In order to ensure high accuracy and reliability of rainfall data measured by TBRs, we recommend performing regular (at least weekly) maintenance and frequent lab and/or field testing of volumetric calibration.

\section{ACKNOWLEDGEMENTS}

The authors would like to thank the Overholt Drainage Education and Research Program, Department of Food, Agricultural and Biological Engineering, The Ohio State University; the USDA-ARS Soil Drainage Research Unit at Columbus, $\mathrm{OH}$ and the USDA-ARS Grassland, Soil and Water Research Laboratory at Temple, TX for funding and facilitating the experiments conducted for this manuscript. We also thank Vilmos Vasvàri, Institute of Urban Water Management and Landscape, Graz, Austria; Alan Flint, Research Hydrologist, USGS, Sacramento, CA; Scott Stephens, Meteorologist, NOAA's National Climatic Data Center, Asheville, NC; Claude Lelièvre, Enviromet International Inc.; and Laura Cook, Observing Service Division of NWS for their comments and suggestions during the study. The authors would like to recognize the contributions of M. J. Heckel, Justin McBride, and Lindsay Pease in laboratory and field work, and Dr. Asmita Murumkar, IIT Roorkee, India in internal review of the manuscript. We 
would also like to thank Dr. Rafiq Islam, The Ohio State University South Centers for his valuable guidance with respect to statistical analyses presented in this manuscript.

\section{REFERENCES}

Alena, T.R., Appleton, J.S., Serstad, W.H., 1990. Measurement accuracy enhancement of tipping bucket rain gauges at high rainfall rates. In Preprints, Conf. on Operational Precipitation Estimation and Prediction, Anaheim, CA. Amer. Meteorol. Soc. 16-111.

Andréassian, V., Perrin, C., Michel, C., Usart-Sanchez, I., Lavabre, J., 2001. Impact of imperfect rainfall knowledge on the efficiency and the parameters of watershed models. J. Hydrol. 250 (1), 206-223. http://dx.doi.org/10.1016/S0022-1694(01)00437-1.

Baffaut, C., Dabney, S. M., Smolen, M., Youssef, M. A., Bonta, J. V., Chu, M. L., Guzman, J. A., Shedekar, V. S., Jha, M. K., Arnold, J. G., 2015 (in press). Hydrologic and water quality modeling: spatial and temporal considerations. Trans. ASABE (Accepted January 2015).

Barring, L., 1992. Comments on "Breakpoint representation of rainfall". J. Appl. Meteorol. 31: 1521-1524. http://dx.doi.org/10.1175/1520-0450(1992)031\%3C1520:COROR\%3E2.0.CO;2.

Calder, I. R., Kidd, C. H. R., 1978. A note on the dynamic calibration of tipping-bucket rain gauges. J. Hydrol. 39 (3-4), 383-386. http://dx.doi.org/10.1016/0022-1694(78)90013-6.

Chaplot, V., Saleh, A., Jaynes, D. B., 2005. Effect of the accuracy of spatial rainfall information on the modeling of water, sediment, and NO 3-N loads at the watershed level. J. Hydrol. 312 (1), 223-234. http://dx.doi.org/10.1016/j.jhydrol.2005.02.019.

Ciach, G. J., 2003. Local random errors in tipping-bucket rain gauge measurements. J. Atmos. Ocean. Tech. 20(5), 752-759. http://dx.doi.org/10.1175/1520-0426(2003)20\%3C752:LREITB\%3E2.0.CO;2.

Colli, M., Lanza, L.G., La Barbera, P., Chan, P. W., 2014. Measurement accuracy of weighing and tipping-bucket rainfall intensity gauges under dynamic laboratory testing. Atmos. Res. 144, 186-194. http://dx.doi.org/10.1016/j.atmosres.2013.08.007.

Cook, L. A., 2010. E-mail communication dated 07/16/2010. Current statistics on weather stations. 
Costello, T. A., Williams, H. J., 1991. Short duration rainfall intensity measured using calibrated time-of-tip data from a tipping bucket rain-gage. Agric. For. Meteorol. 57 (1-3), 147-55. http://dx.doi.org/10.1016/01681923(91)90083-3.

Edwards, L. J., Jackson, W. D., Fleming, P. M., 1974. Tipping bucket gauges for measuring runoff from experimental plots. Agric. Meteorol. 13, 189-201. http://dx.doi.org/10.1016/0002-1571(74)90046-6.

Fankhauser, R., 1997. Measurement properties of tipping bucket rain gauges and their influence on urban runoff simulation. Water Sci. Tech. 36 (8-9), 7-12. http://dx.doi.org/10.1016/S0273-1223(97)00625-2.

Fankhauser, R., 1998. Influence of Systematic Errors from Tipping Bucket Rain Gauges on Recorded Rainfall Data. Water Sci. Tech. 37 (11), 121-129. http://dx.doi.org/10.1016/S0273-1223(98)00324-2.

Groisman P.Y., Peck, E.L., Quayle, R.G., 1999. Intercomparison of recording and standard nonrecording U.S. gauges. J. Atmos. Ocean. Tech. 16, 602-609. http://dx.doi.org/10.1175/15200426(1999)016\%3C0602:IORASN\%3E2.0.CO;2.

Groisman, P.Y., Legates, D.R., 1994. The accuracy of United States precipitation data. Bull. Amer. Meteorol. Soc. 75 (3), 215-224. http://dx.doi.org/10.1175/1520-0477(1994)075\%3C0215:TAOUSP\%3E2.0.CO;2.

Habib, E. H., Meselhe, E. A., Aduvala, A. V., 2008. Effect of Local Errors of Tipping-Bucket Rain Gauges on Rainfall-Runoff Simulations. J. Hydrol. Eng. 13 (6), 488-496. http://dx.doi.org/10.1061/(ASCE)10840699(2008)13:6(488).

Habib, E., Krajewski, W. F., Kruger, A., 2001. Sampling errors of tipping-bucket rain gauge measurements. J. Hydrol. Eng. 6 (2), 159:166. http://dx.doi.org/10.1061/(ASCE)1084-0699(2001)6:2(159).

Harmel, R. D., Haney, R. L., Smith, D. R., White, M., King, K. W., 2014. USDA-ARS Riesel Watersheds, Riesel, Texas, USA: Water quality research database. Water Resour. Res. 50, 8374-8382. http://dx.doi.org/10.1002/2013WR015191.

Harmel, R.D., King, K.W., Richardson, C.W., Williams, J.R., 2003. Long-term precipitation analyses for the central Texas Blackland Prairie. Trans. ASAE 46, 1381-1388. http://dx.doi.org/10.13031/2013.15449.

Humphrey, M.D., Istok, J. D., Lee, J.Y., Hevesi, J.A., Flint, A.L., 1997. A new method for automated dynamic calibration of tipping-bucket rain gauges (Notes and Correspondence). J. Atmos. Ocean. Tech. 14, 1513-1519.

Krajewski, W. F., Smith, J. A., 2002. Radar hydrology: rainfall estimation. Adv. in Water Resour. 25 (8), 13871394. http://dx.doi.org/10.1016/S0309-1708(02)00062-3. 
La Barbera P., Lanza, L., Stagi, L., 2002. Tipping bucket mechanical errors and their influence on rainfall statistics and extremes. Water Sci. Tech. 45 (2), 1-9.

Lanza, L. G., Stagi, L., 2009. High resolution performance of catching type rain gauges from the laboratory phase of the WMO field intercomparison of rain intensity gauges. Atmos. Res. 94, 555-563. http://dx.doi.org/10.1016/j.atmosres.2009.04.012.

Lanza, L. G., Vuerich, E., 2009. The WMO field intercomparison of rain intensity gauges. Atmos. Res. 94, 534-543. http://dx.doi.org/10.1016/j.atmosres.2009.06.012.

Larson, L. W., Peck, E. L., 1974. Accuracy of precipitation measurements for hydrologic modeling. Water Resour. Res. 10 (4), 857-863. http://dx.doi.org/10.1029/WR010i004p00857.

Legates, D. R., 1987. A Climatology of Global Precipitation. Publ. in Climatology, University of Delaware. 40, 85.

Legates, D. R., 1992. The need for removing biases from rain and snow gauge measurements. Pp. 144-151 IN: Proc. Snow Watch '92. Canadian Climate Centre, World Meteorological Organization, and Institute for Space and Terrestrial Science, Niagara-on-the-Lake, Ontario.

Legates, D. R., DeLiberty, T. L., 1993. Measurement biases in the United States rain gauge network. Pp. 547-557 IN: Proc. Symposium on Geiographic Information Systems and Water Resources, Mobile, Alabama.

Legates, D. R., Deliberty, T. L., 1993. Precipitation Measurement Biases in the United-States. Water Resour. Bull. 29 (5), 855-61. http://dx.doi.org/10.1111/j.1752-1688.1993.tb03245.x.

Legates, D. R., Willmott, C. J., 1990. Mean seasonal and spatial variability in gauge-corrected, global precipitation. Int. J. Climatol. 10, 111-127. http://dx.doi.org/10.1002/joc.3370100202.

Lopes, V. L., 1996. On the effect of uncertainty in spatial distribution of rainfall on catchment modelling. Catena. 28 (1), 107-119. http://dx.doi.org/10.1016/S0341-8162(96)00030-6.

Marsalek, J., 1981. Calibration of the tipping-bucket rain gauge. J. Hydrol. 53 (3-4), 343-354.

Michaud, J. D., Sorooshian, S., 1994. Effect of rainfall-sampling errors on simulations of desert flash floods. Water Resour. Res. 30 (10), 2765-2775.

Molini, A., Lanza, L.G., La Barbera, P., 2005. The impact of tipping-bucket rain gauge measurement errors on design rainfall for urban-scale applications. Hydrol. Process. 19 (5), 1073-1088. http://dx.doi.org/10.1002/hyp.5646.

Neff, E. L., 1977. How much rain does a rain gauge gage? J. Hydrology 35, 213-220. 
Niemczynowicz, J., 1986. The dynamic calibration of tipping-bucket rain gauges. Nord. Hydrol. 17 (3), 203-214.

Parsons, D. A., 1941. Calibration of a Weather Bureau tipping-bucket gauge. Mon. Wea. Rev. 69, 205-208. http://dx.doi.org/10.1175/1520-0493(1941)069\%3C0205:COAWBT\%3E2.0.CO;2.

Rauch, W., Thurner, N., Harremoës, P., 1998. Required accuracy of rainfall data for integrated urban drainage modeling. Water Sci. Tech. 37 (11), 81-89. http://dx.doi.org/10.1016/S0273-1223(98)00319-9.

Sansom, J., Gray, W. R., 2002. The Optimization and Calibration of a Rain Intensity Gauge. J. Atmos. Ocean. Tech. $19,3-20$.

Sevruk, B., 1996. Adjustment of Tipping-Bucket Precipitation Gauge Measurements. Atmos. Res. 42 (1-4), 237246. http://dx.doi.org/10.1016/0169-8095(95)00066-6.

Sevruk, B., Hamon, W. R., 1984. International comparison of national precipitation gauges with a reference pit gauge. WMO Instruments and Observation Methods. Report No. 17, 111.

Shedekar, V. S., King, K. W., Brown, L. C., Fausey, N. R., Heckel, M. J., 2009. Measurement errors in tipping bucket rain gauges under different rainfall intensities and their implication to hydrologic models. Proc. of the 2009 Annual International Meeting of the ASABE, Reno, Nevada. Paper Number: 097368.

Sieck, L. C., Burges, S. J., Steiner, M., 2007. Challenges in Obtaining Reliable Measurements of Point Rainfall. Water Resour. Res. 43 (1), W01420. http://dx.doi.org/10.1029/2005WR004519.

Sun, X., Mein, R. G., Keenan, T. D., Elliott, J. F., 2000. Flood estimation using radar and raingauge data. J. Hydrol. 239 (1), 4-18. http://dx.doi.org/10.1016/S0022-1694(00)00350-4.

Upton, G. J. G., Rahimi, A. R., 2003. On-Line Detection of Errors in Tipping-Bucket Raingauges. J. Hydrol. 278 (14), 197-212. http://dx.doi.org/10.1016/S0022-1694(03)00142-2.

Vasvàri, V., 2005. Calibration of Tipping Bucket Rain Gauges in the Graz Urban Research Area. Atmos. Res. 77 (14), 18-28. http://dx.doi.org/10.1016/j.atmosres.2004.12.012.

Wildt, A. R., Ahtola, O., 1978. Analysis of Covariance. SAGE Publications, Inc., Thousand Oaks, CA.

WMO., 1981. Guide to hydrologic practices. Vol. 1: Data acquisition and processing, WMO-No. 168. $4^{\text {th }}$ ed., World Meteorological Organization, Geneva, Switzerland.

Wood, S. J., Jones, D. A., Moore, R. J., 2000. Accuracy of rainfall measurement for scales of hydrological interest. Hydrol. Earth Syst. Sci. 4(4), 531-543. 
Yu, B., Ciesiolka, C. A. A., Rose, C. W., Coughlan, K. J., 1997. A note on sampling errors in the rainfall and runoff data collected using tipping bucket technology. Trans. ASAE 40 (5), 1305-1309.

Zhu, H. J., Schilling, W., 1996. Simulation errors due to insufficient temporal rainfall resolution-Annual combined sewer overflow. Atmos. Res. 42 (1), 19-32. http://dx.doi.org/10.1016/0169-8095(95)00050-X.

Zhu, H., Krause, C. R., Derksen, R. C., Brazee, R. D., Zondag, R., Fausey, N. R., 2004. Real-time measurement of drainage from pot-in-pot container nurseries. Trans. ASAE $47 \quad$ (6), $1973-1979$. http://dx.doi.org/10.13031/2013.17810. 